\title{
Development and application of predictive models of surface water extent to identify aquatic refuges in eastern Australian temporary stream networks
}

\author{
Songyan. Yu (于松延) ${ }^{1}$, Nick. R. Bond ${ }^{2}$, Stuart. E. Bunn ${ }^{1}$, and Mark. J. Kennard ${ }^{1}$ \\ ${ }^{1}$ Australian Rivers Institute and School of Environment and Science, Griffith University, \\ Nathan, Queensland 4111, Australia. ${ }^{2}$ Centre for Freshwater Ecosystems, La Trobe University, \\ Wodonga, Victoria 3689, Australia.
}

Corresponding author: Songyan Yu (songyan.yu@griffithuni.edu.au)

\section{Key Points:}

- We propose a field method for surface water assessment and develop predictive models of spatio-temporal variations in surface water extent

- Simulated long-term variations in surface water extent were highly dynamic through space and time

- Model outputs can inform the identification and prioritization of aquatic refuges to sustain aquatic biota

This is the author manuscript accepted for publication and has undergone full peer review but has not been through the copyediting, typesetting, pagination and proofreading process, which may lead to differences between this version and the Version of Record. Please cite this article as doi: 10.1029/2019WR025216

This article is protected by copyright. All rights reserved. 


\begin{abstract}
Many organisms living in temporary streams rely on remnant surface water to survive during extended dry periods and recolonize newly established habitats when flow resumes. However, research on the spatio-temporal variations of surface water extent for entire river networks is scarce. In this study, we first present a new field method for rapid surface water assessment. Next, we develop predictive models relating observed water extent to environmental attributes at a large number of surveyed stream segments $(n=241)$ in eastern Australian coastal catchments. We use the models to predict daily variations in surface water dynamics throughout entire river networks over the period of 1911-2017, based on available long-term environmental attributes influencing hydrological processes. We find descriptors of surface water extent can be accurately predicted based on robust internal and external validations. Environmental predictor variables representing water gaining processes were more important in predicting surface water extent than variables representing water losses. Simulated long-term variations in surface water extent were highly dynamic through space and time, particularly in inland streams, which were predicted to be the driest on average. Total stream length with surface water ranged from 8,974 to $13,742 \mathrm{~km}$ across the study period. Our study presents a novel and practical approach to quantifying and predicting variations in surface water extent, with potential applicability to other parts of the world. The simulated surface water extent through space and time can be used to identify and prioritize potential aquatic refuge areas that sustain aquatic biodiversity in river networks during extended dry periods.
\end{abstract}

\title{
1 Introduction
}

Temporary streams are streams in which surface water flow ceases and surface water may disappear for some period of most years (Uys \& O'Keeffe, 1997). They constitute more than half of the global river network extent (Acuña et al., 2017; Datry et al., 2014; Leigh et al., 2015) and are considered the most common and hydrologically dynamic of all freshwater ecosystems (Larned et al., 2010). Temporary streams periodically experience dry spells of varying frequency and duration, during which surface water habitats contract and often become restricted to disconnected pools or completely dry (Hermoso et al., 2013b). Most obligate aquatic species rely on remnant aquatic habitats as refuges to survive extended dry periods (Arthington et al., 2005; Magoulick \& Kobza, 2003). These populations subsequently act as important source populations for recolonization when flows resume and play a key role in population growth (Arthington et al., 2010). Therefore, biodiversity persistence and community structure in temporary stream systems can be strongly influenced by the existence, size, number, spatial arrangement, and temporal dynamics of aquatic refuges within river networks (Costigan et al., 2016; Leigh et al., 2016; Leigh \& Datry, 2016; Sedell et al., 1990).

An increasing number of studies have used streamflow characteristics, such as timing, frequency and duration of zero flow periods, to infer the potential spatio-temporal dynamics of surface water presence (González-Ferreras \& Barquín, 2017; Jaeger et al., 2014; Snelder et al., 2013; Yu et al., 2018). However, these streamflow characteristics are binary indicators of surface water presence (flowing vs. non-flowing), and do not adequately characterize variation in surface water extent through space and time. Research quantifying the dynamics and environmental determinants of variation in surface water extent throughout river networks is scarce (but see Jaeger et al., 2019). In addition to surface flow, stream channel characteristics (e.g. orientation, degree of incision, slope, riparian cover), local geology and streambed substrate, connectivity to 
hyporheic flow or groundwater, and climatic factors (e.g. precipitation, solar radiation and potential evaporation), can all influence the size, spatial arrangement and temporal persistence of surface water bodies once flows cease (Buttle et al., 2012; Costigan et al., 2017). However, the potential influence of these factors on surface water dynamics over broad spatial and temporal scales is poorly understood. Furthermore, these factors also interact with each other, with a common recognition that the broad-scale structure controls the finer-scale processes (Buttle et al., 2012; Costigan et al., 2016; Frissell et al., 1986; Montgomery, 1999). Therefore, it is important to look at the full-range of spatio-temporal conditions and the interactions between spatiotemporal scales to understand the dynamics of surface water extent.

Remote sensing has been used to study surface water extent (Bishop-Taylor et al., 2017; Hermoso et al., 2012), but limitations of satellite image resolution restrict its application to floodplains or wide river channels with low vegetation canopy cover. Other approaches use onground mapping (Jaeger \& Olden, 2012; Stanley et al., 1997; Turner \& Richter, 2011) and/or time-lapse photography taken by fixed in-situ cameras (Costigan et al., 2017) to identify or track changes in the locations of surface water within a catchment. These approaches are appropriate over small spatial extents and short time frames, but are difficult to scale up to a larger area and to quantify surface water through space and time. Alternatively, statistical modelling may be a realistic and promising method to predict surface water extent over large spatial scales and long periods. This is because multiple-scale environmental factors have been identified to influence surface water extent (Buttle et al., 2012; Costigan et al., 2016), and geospatial datasets of longterm environmental attributes are increasingly available around the world. Machine learning methods, such as random forest (RF) modelling, have frequently been used in studies predicting spatial patterns in river characteristics (e.g. see Bond \& Kennard, 2017, Haddadchi et al. 2018) and has shown generally better performance than other methods such as linear regression (Booker \& Snelder, 2012). RF models have recently been used to predict the probability of flow permanence (González-Ferreras \& Barquín, 2017; Jaeger et al., 2019; Snelder et al., 2013) and annual surface water presence-absence (Jaeger et al., 2019) throughout river networks. However, predictive statistical modelling has never, to our knowledge, been used to quantify variation in continuous measures of surface water extent throughout entire river networks at a daily time step over long (multi-decadal) time periods. One of the biggest barriers to this kind of research is the difficulty in obtaining observed data of surface water extent across river networks, ranging from headwaters to the main stems, due to the aforementioned limitations of measurements.

Here we first present a new field method for rapid surface water assessment. Next, we model variations in surface water extent throughout river networks in eastern Australia, by developing statistical models to predict surface water extent as a function of catchment physiography and climate-related drivers. We calibrated the models using surface water extent data sampled bimonthly at 241 stream segments in 2018 . We evaluated the predictive transferability of developed models through space and time using internal and external validation datasets. The derived statistical models were then used to develop predictions of daily surface water extent for all stream segments across the entire study area over the period of 1911-2017. The approach proposed here has potential applicability to other catchments around the world and can help to identify important surface water refuges for biodiversity and targeted conservation management. 


\section{Study area}

This research was conducted in five major coastal river catchments of south-eastern Queensland (SEQ) in eastern Australia (Figure 1), comprising an area of 21,331 $\mathrm{km}^{2}$. SEQ has 7,229 stream segments with an average length of $2.3 \mathrm{~km}$ and corresponding sub-catchments in the Australian Hydrological Geospatial Fabric (Geofabric; Stein et al., 2014) out of 1.4 million stream segments mapped for Australia. A stream segment was defined as a section of DEMderived (1:250000 scale) streamline between two consecutive breaks of confluences, distributary nodes and water bodies (Stein et al., 2014). SEQ is a region of transitional temperate to subtropical climate with substantial inter- and intra-annual variation in discharge, resulting in a range of flow regimes with many streams being intermittent to varying degrees (Yu et al., 2018). Stream segments intersecting lakes and reservoirs and those subject to tidal influence were considered to always contain $100 \%$ surface water.

\section{Methodology}

\subsection{Site selection and datasets used for model training and validation}

Field sampling of surface water extent for model training and validation was undertaken during 2018. Rainfall within the 2018 sampling period was generally representative of the range of long-term conditions (i.e. within the 10th - 90th percentiles of total monthly rainfall values), although rainfall was higher than average during February and October, and lower than average for the rest of the year (Figure S1). Surface water extent was sampled at 241 sites (stream segments) between January and November in 2018 (Figure 1), using the method described in Section 3.2. Eighty-four of these sites were sampled in January / February. A subset of sites, ranging from 26 and 37 sites, were sampled bimonthly thereafter (Figure 2). These 241 sites were used to train the predictive model (hereafter termed 'training' sites). We used a stratifiedrandom sampling strategy similar to that used by Steward et al. (2012) to select candidate sampling sites. This involved dividing the south eastern Queensland study area into 24 evenlysized cells (Figure 1) and randomly selecting candidate sampling sites with the proviso that sites could be accessed by road. This resulted in a set of sampling sites for model training that were widely dispersed throughout the study area, encompassing a representative range of stream environmental characteristics and hydrological conditions (Figure 1). A subset of 15 randomlyselected training sites (hereafter term 'internal validation' sites; Figure 1, Figure 2) was sampled bimonthly and was used to evaluate the stability of model predictions through time. An additional set of 10 randomly-selected new sites were sampled bimonthly and used to externally validate the model performance (hereafter termed 'external validation' sites; Figure 1, Figure 2), enabling the assessment of model predictive accuracy and transferability through space and time.

The range of variation in observed surface water extent was generally similar across the three sampling data sets (i.e. the training, internal, and external validation data set), with most sites either very dry or very wet, and very few sites in between (Figure S2). However, there was a noticeable difference in the training data set having a smaller proportion of drier sites but a higher proportion of wetter sites than the two validation samples (Figure S2).

The robustness and strength for potential extrapolation of statistical modelling partly rely on whether the training sites are representative of environmental variation throughout the entire river network. The 241 training sites were checked for their representativeness by comparing the frequency distributions of environmental characteristics for sampled stream segments with those 
of all stream segments. Closely matching frequency distributions implies adequate representativeness. We evaluated representativeness along gradients of catchment area, flow intermittency, stream size (Strahler stream order), river disturbance index (RDI), the mean slope of the stream segment (slope) and the average elevation of the associated sub-catchment (elevation). RDI was computed based on flow regime disturbance caused by impoundments, flow diversions and levee banks, and catchment disturbance due to urbanization, road infrastructure and land use activities (Stein et al., 2002). RDI takes a value from 0 to 1, and a lower RDI value means less human disturbance for a stream segment. All these six environmental variables were sourced from the Geofabric (Stein et al., 2014).

\subsection{Method for rapid surface water assessment in the field}

Surface water extent was estimated as the lineal extent of surface water present along the thalweg of each stream segment. During field sampling, if a stream segment was flowing, its surface water extent was recorded as $100 \%$. When a stream segment was not flowing, we walked along at least $50 \%$ of the segment and estimated surface water extent by 1) making waypoints using a GPS device at the start and end point of each patch of surface water or dry stream bed, respectively, and 2) calculating in ArcGIS 10.3 (ESRI, 2002) the total length of wetted sections and expressing as a proportion of total segment length. Only surface water pools longer than $1 \mathrm{~m}$ were counted as this length approximated the precision of the GPS device (Garmin Pollard GPS unit). The same person did all the measurements in the field.

Lineal estimates of surface water extent were used in this study, as it takes considerably longer to measure the areal extent of surface water. To evaluate the appropriateness of a lineal measure of surface water extent, we compared lineal and areal measures of surface water extent using Google Earth imagery for 12 randomly selected stream segments whose channel could be clearly seen. The median length of the 12 stream segment is $2.7 \mathrm{~km}$, ranging from 0.5 to $7.5 \mathrm{~km}$. The lineal surface water extent was measured as the total length of the stream channel with surface water present along the thalweg. The areal surface water extent was quantified by summing up areas (length $\times$ average wetted width) of all surface water present in each stream segment. We then calculated the coefficient of determination $\left(\mathrm{R}^{2}\right)$ to represent the agreement between the two measures. The lineal measure of surface water extent was strongly related to its areal measure $\left(\mathrm{R}^{2}=0.80, \mathrm{p}<0.001\right)$ (Figure $\mathrm{S} 3$ ), indicating that this was an appropriate proxy for use in our study.

The minimum length of $50 \%$ of a given stream segment required to estimate surface water extent was based on an evaluation of changes in bias (deviation of an estimate to the true value) and precision (degree of variation in the estimate) within increasing stream distance sampled. Using Google Earth imagery for the same 12 stream segments described above, we randomly sampled different fixed lengths of stream in increments of $10 \%$ of the total segment length and calculated lineal surface water extent. This calculation was achieved using a customized R script. This script simplifies a stream segment as a line section composed of a series of dry/wet sections, and then randomly selects a fixed length of the section along the stream and calculates the proportion of the selected section length with surface water as lineal surface water extent. We repeated this calculation process 1000 times for each cumulative $10 \%$ increment and compared the sampled surface water extent with the actual surface water extent for the entire stream segment. Bias for each $10 \%$ cumulative increment of total segment length was calculated as the mean absolute percentage difference between the estimated values 
generated over the 1000 randomizations and the 'true' value. Precision for each cumulative increment was represented by the coefficient of variation (CV). Averaged across the 12 sites (Figure S4), bias in estimates of surface water extent were $\leq 10 \%$ for each cumulative increment of sampling effort (length of stream), but precision in these estimates was relatively low until about $50 \%$ of stream distance had been sampled (e.g. CV $\leq 0.25$ ). We, therefore, used $50 \%$ of stream distance as a minimum level of sampling effort for field sampling of surface water extent.

\subsection{Environmental predictor variables}

We selected a range of candidate predictor variables with clear conceptual links (Buttle et al., 2012; Costigan et al., 2016) to processes potentially influencing variation in the occurrence of surface water in stream channels. To account for spatial and temporal dynamics of surface water extent, environmental attributes that represent both water gains and losses and that influence surface water persistence at multiple spatial scales were considered. Initially, 42 candidate variables were identified, but were reduced to 18 after removal of highly correlated variables (absolute Pearson's correlation coefficients $r>0.75$ ). The final set of environmental predictor variables (Table 1) describe the following: long-term and short-term climate (average annual mean rainfall and average driest quarter mean temperature; average rainfall and actual evapotranspiration over the last 10 days); hydrology (mean discharge over the last 10 days, estimated using a water balance model AWRA-L Version5, and accumulated soil water surplus and number of days since cease to flow); catchment soil properties (soil saturated hydraulic conductivity, average solum plant available water holding capacity and catchment storage), which is indicative of plant transpiration or potential groundwater discharge to surface water; and catchment geology topography (maximum upstream elevation, catchment shape, subcatchment average slope) and anthropogenic extraction (river disturbance index). We also used stream order to indicate stream size and catchment area, and stream substrate properties to describe the potential vertical water losses from the stream. The degree of flow intermittency, represented by mean monthly zero flow duration per year, was also included to account for the overall possibility of a stream being intermittent.

Most of the predictor variables were sourced from Geofabric (Stein et al., 2014), except for the temporal variables, including CatRain10, Discharge10, SubETA10 and DaysNoFlow and FlowInterm. Antecedent rainfall and actual evapotranspiration were obtained from the Australian Bureau of Meteorology (http://www.bom.gov.au/water/landscape). They serve as inputs into the AWRA-L model, a daily gridded distributed water balance model developed at a national scale (van Dijk, 2010; Viney et al., 2015), to generate runoff as output. Antecedent discharge data for each stream segment were obtained from the runoff output from the AWRA-L model using the same methods developed by $\mathrm{Yu}$ et al. (2018). The degree of flow intermittency was sourced from Yu et al. (2018).

\subsection{Statistical modelling}

Random forest (RF) modelling was conducted relating surface water extent to a wide range of environmental variables. Observed surface water extent at all sampling sites was originally quantified as continuous values (\% surface water extent), and we refer to the model of the continuous variable as the "continuous surface water model". We also transformed this measure into two binary variables by discretizing based on two different thresholds. One threshold of $0 \%$ surface water extent was selected to separate completely dry sites from all 
others and typifies a variable representing presence/absence of surface water. The other threshold of $50 \%$ wetted length was selected to separate sites with $>50 \%$ from sites with water status $\leq$ $50 \%$ and typifies a variable representing the potential refugial quality. A similar approach was adopted by Bishop-Taylor et al. (2017), in which they identified pixels that contained water for greater than $50 \%$ of satellite observations as potential habitat layers. We refer to the model of the $0 \%$ threshold as the "surface water presence/absence model". The 50\% threshold allows for detection of stream segments that are more likely to provide high-quality aquatic refuges in terms of water quantity and quality (hereafter, termed "high-quality refuge model"). Studies show that as surface water extent decreases, some ecologically important water quality parameters degrade quickly, such as water temperature and dissolved oxygen (Magoulick \& Kobza, 2003). Predation risk can also increase considerably reducing the habitat suitability of waterholes as refuges as they become smaller (Magoulick \& Kobza, 2003). In this study, we, therefore, developed RF models for surface water extent in the three different response variable types, including one continuous, and two binary response variables. The reduced variance in the binary models also served to potentially increase model performance by reducing sensitivity to sampling uncertainty, albeit with a loss of information about the degree of habitat variability.

Multicolinearity and spatial and temporal autocorrelation among predictors have strong impacts on identifying the relative importance of predictors (Snelder et al., 2013). We applied the procedure of Svetnik et al. (2004) to reduce the RF model to the most parsimonious set of predictors. The procedure recursively removes the least-important variable from the model based on a cross-validation process and tests whether the reduced model still has acceptable prediction performance. We used "one standard error rule" (Breiman et al., 1984) to select the reduced model that has prediction performance within the error generated from the cross-validation process for the best performance model, and that also has the least number of predictors. The reduced model was used for subsequent analysis. The RF modelling was conducted using the $\mathrm{R}$ package randomForest (Liaw \& Wiener, 2002).

The structure of the RF model can be examined using importance measures, which indicate the contribution of predictors to model performance. They are calculated from the degradation in model performance when a predictor is randomly permuted (Breiman, 2001). For the continuous response variable type, the increase in mean squared error (IncMSE) was used to measure variable importance, while for the two binary response variable types, the increase in misclassification rate (IncMR) was applied. To enable comparison among response variables, the average rank importance of retained predictors was used.

For the two binary response variable types, the performance of a classification model is sensitive to the probability threshold that is applied (Freeman \& Moisen, 2008). We applied a threshold selection method of MaxKappa to choose the best threshold for the RF modelling. MaxKappa is to select the threshold that results in the maximum value of Cohen's Kappa (Cohen, 1960). Kappa measures the agreement between two classifications and takes a value between 0 (no agreement) and 1 (complete agreement).

The model performance was evaluated using a leave-one-out cross validation procedure and was characterized by the mean absolute error (MAE), the root-mean-square error (RMSE), and the Nash-Sutcliffe model efficiency coefficient (NSE; Nash \& Sutcliffe, 1970) for the continuous response variable, and by Cohen's Kappa (Kappa), correct classification rate (CCR), and receiver operating curves (ROC) for the binary response variables. MAE is the average absolute difference between the observed and predicted surface water extent. RMSE is the square 
root of the difference between the observed and predicted surface water extent. Both MAE and RMSE range from 0 to $+\infty$ with lower values indicating lower error. NSE was defined for hydrological models and is used to assess the predictive performance of quantitative models, including physically-based and statistical models. NSE takes values from - $\infty$ to 1 and values closer to 1 indicating greater model accuracy. CCR is the ratio of correctly classified (predicted) cases to the total cases, with values ranging from 0 (all falsely classified) to 1 (all correctly classified). ROC is independent of the threshold for the two binary response variables. ROC plots show the true positive rate (sensitivity) against the false positive rate (1-specificity) as the threshold varies from 0 to 1 (Hanley \& McNeil, 1982). The area under the ROC curve (AUC) is a good measure of overall model performance that is independent of probability threshold, with good models having an AUC near 1, while poor models have an AUC near 0.5 (Freeman \& Moisen, 2008). In the cross-validation step, we withheld one observation in turn from the training dataset used to fit the RF models. We then used the developed RF model to independently predict the probability of the withheld observation. The cross-validated probabilities were then used to identify the appropriate probability threshold with the abovementioned selection method (i.e. MaxKappa). The identified probability threshold was applied to both internal and external validations.

\subsection{Model validation}

We evaluated how well the developed models were able to predict surface water extent for new time periods using internal validation as well as at new sites using external validation by comparing the match between the expected and observed surface water extent. We applied the same metrics as in the model calibration process. Furthermore, for classification models, we investigated the prediction errors in detail by differentiating commission error from omission error. Commission error is the wrong prediction when surface water is absent, and omission error is the wrong prediction when surface water is present. This differentiation can interpret the modelling predictions in a more informative way and provide valuable insights into the applicability of constructed models (Rose et al., 2016).

\subsection{Model application to identify potential aquatic refuges}

After the construction of the models, we further extrapolated all three models to the entire study area to simulate daily surface water extent for every stream segment over the period of 1911 - 2017. To quantify spatial patterns of surface water extent, we calculated a summary metric of 1) the annual mean surface extent for the continuous model, 2) the annual mean number of days with surface water present for the surface water presence/absence model, and 3) the annual mean number of days with surface water extent $>50 \%$ for the high-quality refuge model, from 1911 - 2017. We also estimated surface water presence for each stream segment in 2018 specifically, enabling a comparison with the empirically observed surface water presence over the sampling period. Finally, we quantified the temporal dynamics of daily variation in total surface water extent for each of the three response variables over the period of 1911-2017. The total length of stream containing surface water on each day was calculated by multiplying simulated daily surface water extent (" $\%$ " for the continuous surface water variable and " $0 / 1$ " for the surface water presence/absence and high-quality refuge variables) by the corresponding stream segment length. 


\section{Results}

\subsection{Representativeness of training sites}

Five of the six attributes, including flow intermittency, catchment area, elevation, slope, and RDI, showed similar distributions between the total streams and the sampled streams (Figure 3 ). The only exception was the Strahler stream order where first order streams were under represented, while second and third order streams were oversampled by $30 \%$ (Figure 3). Almost all the sampled streams have values of RDI $<0.5$, suggesting that the associated data set used for model development was only slightly influenced by human activities.

\subsection{Model training}

Statistical models were constructed for each of the three response variables. The model performance indicated that all three response variables could be predicted reasonably accurately using the constructed RF models. More specifically, for the continuous response variable, the reduced RF model had an MAE value of 0.22, a RMSE value was 0.31, and a NSE value was 0.51 (Table 2), with a total of seven out of the 18 predictor variables retained in the final model (Table 3). Between the two classification models, the one for the high-quality refuge (i.e. the binary variable with threshold of 50\%) outperformed the other in terms of model performance, with the AUC, CCR and Kappa values of 0.90, 0.82, 0.62, respectively, compared to the same metric values of $0.86,0.84$ and 0.45 for the surface water presence/absence model (Table 2). However, the outperformance of the high-quality refuge model was achieved with eight retained environmental variables, while only four variables were retained for the presence/absence model (Table 3).

The three model approaches displayed a high degree of congruence in retained environmental variables (Table 3). Firstly, variables with links to water gains, water losses, and surface water persistence were all retained in the three reduced models. Next, among the nine out of 18 variable predictors contributing significantly to the three models, four of them were shared by all the three RF models.

There was significant spatial variation in model accuracy for each of the three models, but the patterns appeared similar across them. For example, all models had higher accuracy for coastal streams than for inland streams (Figure 4). In addition, the continuous surface water model tended to significantly misrepresent habitat persistence in the Brisbane River catchment (Figure 4a), and it was also true for the two classification models that almost all wrongly predicted sites were found in inland streams (Figure $4 b, c)$, but there was a slight difference between the surface water presence/absence model and the high-quality refuge model. The wrongly predicted sites by the former model were more concentrated in the western part of Brisbane River catchment, while those by the latter model were distributed evenly across inland. Furthermore, for the two classification models commission error was the major error type (Figure 4b, c), suggesting it was more likely that the models predicted surface water to be present when in reality it was absent.

\subsection{Model validation}

In terms of internal validations, all three models performed equally well as or even better than the model fits for calibration. For example, the overall performance for each model (NSE 
for the continuous model and Kappa for the two classification models) were $0.63,0.69,0.73$, while the model fits for calibration were $0.51,0.45$, and 0.62 , respectively (Table 2). There were also noticeable temporal variations in model performance from March to November of 2018, but for most times the internally validated models outperformed the externally validated model (Figure 5). The continuous surface water model tended to slightly overestimate surface water extent (Figure 5a), and the two classification models were more likely to falsely predict water presence (commission errors) than absence (omission errors) (Figure 5b, c).

By contrast, for external validations, none of the three models showed better performance than the trained model (Table 2). For example, the overall performance for each model were $0.14,0.57$, and 0.51 , while the model fits calibration were $0.51,0.42$, and 0.67 (Table 2). Additionally, there was significant variation in the model performance across months, which tended to be worse during the dry period (March - September) and improved in the following wet period (November) (Figure 5). All three models showed higher error rates during external validation (Figure 5).

\subsection{Model applications}

Surface water presence/absence was predicted throughout river networks in SEQ for the year of field sampling in 2018. Figure 6 showed that drier streams tended to be concentrated in the north-western part of the study region, where the majority of streams were predicted to have surface water present for less than 60 days. The coastal streams and main stems were predicted to contain surface water almost all year (> 300 days). The predicted spatial pattern of surface water presence aligned quite well with the observed surface water presence/absence during the field assessment (Figure 6).

Spatial patterns in simulated average long-term $(1911$ - 2017) surface water extent (Figure 7) were similar for each response variable type and also to that observed in 2018 (Figure 6). Spatial patterns in the degree of inter-annual variation in surface water extent were also similar between response variables. For the continuous surface water model, inland streams, especially streams in the western part of the Brisbane River catchment, were predicted to be driest on average (e.g. $<60 \%$ surface water extent on average) and these were the most variable through time(Figure 7a, b). Similarly, these western streams contained surface water for relatively short periods of time per year on average and varied more from year to year, both for surface water presence (Figure 7c, d) and high-quality refuge (Figure 7e, f).

The total length of stream predicted to contain surface water varied substantially through time over the 1911-2017 study period (Figure 8). For the continuous surface water extent variable, the total stream length predicted to contain surface water ranged from 8,974 to 13,742 $\mathrm{km}$ across the study period (mean $11,081 \pm 839 \mathrm{~km}$ ). The total stream length predicted to contain the presence of surface water or high-quality refuges was higher on average $(14,906 \pm 750 \mathrm{~km}$ and 13,693 \pm 808 , respectively) and more variable through time (range: 7,433 - 14,906 km and $10,243-13,693 \mathrm{~km}$, respectively) than the continuous surface water extent variable.

\section{Discussion and conclusions}

It is widely accepted that remnant surface water bodies in the drying phase of temporary streams are critically important for aquatic biota to survive during extended drying periods and also to recolonize suitable habitats after flow resumes (Arthington et al., 2010; Bond et al., 2008; 
Bunn et al., 2006). However, few studies have focused on quantifying long-term spatial and temporal dynamics of surface water extent throughout entire river networks, partly due to the difficulty in measuring surface water extent over broad scales. In this study, we first demonstrate a new field method for rapid surface water assessment, and then present a novel and practical approach to addressing this issue by developing statistical predictive models of surface water extent at a daily time step. This was based on the combined use of field sampling and environmental attributes describing critical hydrological processes hypothesized to influence spatio-temporal variation in surface water extent. Our approach is potentially applicable to other catchments around the world and can help to identify important surface water refuges for biodiversity and targeted conservation management.

\subsection{Model development and validation}

Spatial and temporal variations in surface water extent are governed by interactions between hydrological processes (Costelloe \& Russell, 2014), including inflow from upstream, infiltration through streambed, groundwater inputs, and evapotranspiration (Buttle et al., 2012). To account for these processes, variables representing water gains and losses and surface water persistence were selected when constructing the models, and random forest modelling was applied to explain the non-linear relationships between these environmental variables and spatiotemporal dynamics of surface water extent.

In all three developed models, we found variables representing water gains, such as catchment annual rainfall and annual mean runoff, and surface water persistence, such as the degree of flow intermittency, were more important in predicting surface water extent than variables representing water losses, such as evapotranspiration. This finding is expected in our study area because SEQ can experience rainfall every month with an average annual total of $1063 \mathrm{~mm}$, enabling isolated water pools to become connected. This finding is supported by previous studies (Jaeger et al., 2019; Reynolds et al., 2015) demonstrating that environmental variables related to water gaining processes (e.g. precipitation or snow water equivalent) were relatively more important than water losing processes in variation in streamflow permanence. However, in more arid areas, this is unlikely to be the case. For example, in the arid zone of central Australia, where there can be long time intervals between rainfall events, Costelloe et al. (2007) reported that evaporation was the dominant process determining water loss in the absence of flow, so that the persistence of a waterhole was primarily dependent on its depth when flow ceases. The modelling approach developed here can be used to identify the main processes influencing surface water extent in other regions.

Random forest models were developed for three metrics describing surface water persistence. We then applied both internal and external validation datasets to evaluate 1) the stability of predictions through time and 2) the overfitting and potential of extrapolation of the predictive models, respectively. We observed consistently high model accuracy over time for the internal validations, but model accuracy for the external validations varied from good performance in the wet season to only fair in the dry season. Temporal representativeness of sampling can be one possible source of uncertainty in model development. Almost half of the training sites were visited in the wet season, while the majority of validation sites were sampled in the dry season. This difference in sampling timing meant that the training sites were slightly more skewed towards wetter sites while the validation sites had a higher representation of drier sites (Figure S2). Furthermore, the misalignment in the distribution of observed surface water 
extent between the training sites and validation sites made the sites with higher surface water extent over-represented in the constructed model, leading to underestimation of drier sites.

Commission error predominated in both the internal and external validations (Figure 5), suggesting that all three models tended to over-predict surface water extent. This finding was consistent with Jaeger et al. (2019), where stream sites were prone to be falsely predicted wet by random forest models. Ideally, the models developed in our study could be improved to minimize this source of error by: 1) including more sampling sites encompassing a greater range of environmental conditions for model calibration, and 2) using additional environmental predictor variables to better represent key hydrological processes influencing surface extent, including groundwater and surface water connectivity. Depending on the intended model use and costs associated with making incorrect decisions, commission error can be tolerated or even favored in certain cases (Araújo \& Peterson, 2012; Rose et al., 2016). Taking the surface water presence/absence model as an example, commission error predicts surface water present when it is absent, which leads to potentially wasted limited resources; while omission error predicts surface water absent when present, leaving valuable aquatic refuges unprotected and threatening the survival of aquatic species. High commission errors may lead to protection of habitats where target species may not actually inhabit (Hermoso et al., 2013a). So that the developed models of surface water extent in this study can be well suited to aquatic refuge identification.

\subsection{Model applications}

By combining field sampling and historical long-term environmental variable datasets, we were able to develop robust models of surface water extent and apply them to the entire stream networks in SEQ over the past century. The valid use of predictive models for spatial interpolation and temporal extrapolation ideally requires that samples used to train the models encompass as much of spatial and temporal variability in environmental predictor and response variables as possible (Bond \& Kennard, 2017; Elith \& Leathwick, 2009). In our study, this assumption was supported by the findings that rainfall conditions during the 2018 sampling period were representative of the range of long-term conditions (Figure S1). In addition, the sampling period included two months of extremely high and low rainfall (exceeding the $90^{\text {th }}$ and $10^{\text {th }}$ percentiles, respectively), further enhancing the temporal scope of data used for model training. Furthermore, the 241 training sites represented the full spatial range of environmental predictor variables over the entire river networks (Figure 3).

Our models revealed that the overall stream length predicted to contain surface water varied substantially on a daily basis over the period of 1911-2017 (Figure 8), which confirms the highly dynamic nature of temporary streams that are characterized by recurrent contraction and expansion of surface water within river networks (Jaeger and Olden, 2012). Variations in simulated surface water extent were determined by the strong dynamics of environmental predictor variables influencing water gain (e.g. rainfall) and loss (e.g. evapotranspiration) processes as well as surface water persistence (e.g. stream segment slope) (Buttle et al., 2012; Costigan et al., 2016). Interestingly, there was no long-term trend towards decreased overall surface water extent over the study period, which contrasts with the commonly-expressed concern about a potential shift towards drier river networks due to climate change (Ruhí et al., 2016; Sabo, 2014). Our finding matches with a previous study (Yu et al., 2018) in the same region that demonstrated no clear tendency towards increased flow intermittency over time from 1900-2016. 
The simulation of surface water extent through space and time can be used to identify and prioritize potential aquatic refuge areas for conservation management to sustain aquatic biodiversity in river networks during extended dry periods. Average long-term spatial patterns of simulated surface water extent for all three response variables showed that the coastal and lowland streams had greater surface water extent due to their high flow perenniality. In contrast, permanent surface water habitats in the main stems of river channels located further inland in the western part of SEQ were relatively scarce and were surrounded by a network of drier streams in this region. These areas could be considered as priority aquatic refuges as they could be extremely important for nearby aquatic species to not only survive extended dry periods but also recolonize newly established habitats when flow resumes (Arthington et al., 2005; Arthington et al., 2010; Magoulick \& Kobza, 2003). Recently systematic conservation planning approaches have been widely applied to freshwater ecosystems to efficiently identify high priority refuges for conservation management (Moilanen et al., 2008; Nel et al., 2009), and information on surface water persistence is considered as one of the important inputs (Bishop-Taylor et al., 2017; Hermoso et al., 2012). Therefore, the developed models in this study could be helpful to provide such information to inform the systematic prioritization of aquatic refuges for targeted conservation management to sustain aquatic biodiversity.

We predicted aquatic status not only as a binary variable (e.g. surface water presence/absence) (Jaeger et al., 2019) but also as a continuous variable, making it possible for future studies to further investigate ecological responses to continuous drying process when streams cease to flow. This will enable a better understanding of how aquatic species and communities respond to the gradual reduction of surface water extent. Importantly, this study is especially beneficial for small streams that are often covered by dense vegetation, which prevents the use of remote sensing for mapping surface water, despite this approach being successfully deployed in monitoring larger rivers and wetlands (Alsdorf et al., 2007; Ward et al., 2014). Given that many small streams are also temporary (Fritz et al., 2013), our study demonstrates an approach that can potentially help bridge the gap to identify surface water extent for small streams over a large spatial scale.

In summary, we proposed a new field method for rapid surface water assessment in the field, which showed that only half of a stream segment was required to be sampled and the lineal measure of surface water extent was a good proxy for the areal measure. We also presented a novel approach to quantifying the spatial and temporal patterns of surface water extent by developing robust statistical predictive models. Given that surface water extent is one of the fundamental elements in identifying aquatic refuges, these developed models offer a promising way to incorporate surface water persistence in the future research on applying systematic conservation planning principles to freshwater ecosystems, especially temporary stream systems.

\section{Acknowledgments}

Thanks to Boya Zhang, Ran Cao, Ali Mobadersani, Yintao Jia, Brett Parker, and Ryan Burrows for their invaluable field assistance. Funding for this project came from Griffith University and the China Scholarship Council. We gratefully acknowledge the support of the Griffith University eResearch Services Team and the use of the High Performance Computing Cluster "Gowonda" to complete this research. The sampling data are available from https://github.com/SongyanYu/SurfaceWater. Other data used in this study are available publicly online and the access websites have been listed in the main text where they are first mentioned. 


\section{References}

Acuña, V., Hunter, M. \& Ruhí, A. (2017). Managing temporary streams and rivers as unique rather than second-class ecosystems. Biological Conservation.

DOI:10.1016/j.biocon.2016.12.025

Alsdorf, D. E., Rodríguez, E. \& Lettenmaier, D. P. (2007). Measuring surface water from space. Reviews of Geophysics, 45(2). DOI:10.1029/2006rg000197

Araújo, M. B. \& Peterson, A. T. (2012). Uses and misuses of bioclimatic envelope modeling. Ecology, 93(7): 1527-1539. DOI:doi:10.1890/11-1930.1

Arthington, A. H., Balcombe, S. R., Wilson, G. A., Thoms, M. C. \& Marshall, J. (2005). Spatial and temporal variation in fish-assemblage structure in isolated waterholes during the 2001 dry season of an arid-zone floodplain river, Cooper Creek, Australia. Marine and Freshwater Research, 56(1): 25-35. DOI:https://doi.org/10.1071/MF04111

Arthington, A. H., Olden, J. D., Balcombe, S. R. \& Thoms, M. C. (2010). Multi-scale environmental factors explain fish losses and refuge quality in drying waterholes of Cooper Creek, an Australian arid-zone river. Marine and Freshwater Research, 61(8): 842-856. DOI:https://doi.org/10.1071/MF09096

Bishop-Taylor, R., Tulbure, M. G. \& Broich, M. (2017). Surface-water dynamics and land use influence landscape connectivity across a major dryland region. Ecological Applications, 27(4): 1124-1137. DOI:10.1002/eap.1507

Bond, N. R. \& Kennard, M. J. (2017). Prediction of Hydrologic Characteristics for Ungauged Catchments to Support Hydroecological Modeling. Water Resources Research, 53(11): 8781-8794. DOI:10.1002/2017wr021119

Bond, N. R., Lake, P. S. \& Arthington, A. H. (2008). The impacts of drought on freshwater ecosystems: an Australian perspective. Hydrobiologia, 600(1): 3-16. DOI: $10.1007 / \mathrm{s} 10750-008-9326-\mathrm{Z}$

Booker, D. J. \& Snelder, T. H. (2012). Comparing methods for estimating flow duration curves at ungauged sites. Journal of Hydrology, 434-435: 78-94. DOI:https://doi.org/10.1016/j.jhydrol.2012.02.031

Breiman, L. (2001). Random forests. Machine learning, 45(1): 5-32.

Breiman, L., Friedman, J., Stone, C. J. \& Olshen, R. A. (1984). Classification and regression trees. Wadsworth, Belmont, California.

Bunn, S. E., Thoms, M. C., Hamilton, S. K. \& Capon, S. J. (2006). Flow variability in dryland rivers: boom, bust and the bits in between. River Research and Applications, 22(2): 179186. DOI:10.1002/rra.904

Buttle, J. M., Boon, S., Peters, D. L., Spence, C., van Meerveld, H. J. \& Whitfield, P. H. (2012). An overview of temporary stream hydrology in Canada. Canadian Water Resources Journal, 37(4): 279-310. DOI:10.4296/cwrj2011-903

Cohen, J. (1960). A Coefficient of Agreement for Nominal Scales. Educational and Psychological Measurement, 20(1): 37-46. DOI:10.1177/001316446002000104 
Costelloe, J. F. \& Russell, K. L. (2014). Identifying conservation priorities for aquatic refugia in an arid zone, ephemeral catchment: a hydrological approach. Ecohydrology, 7(6): 15341544.

Costelloe, J. F., Shields, A., Grayson, R. B. \& McMahon, T. A. (2007). Determining loss characteristics of arid zone river waterbodies. River Research and Applications, 23(7): 715-731. DOI:10.1002/rra.991

Costigan, K. H., Jaeger, K. L., Goss, C. W., Fritz, K. M. \& Goebel, P. C. (2016). Understanding controls on flow permanence in intermittent rivers to aid ecological research: integrating meteorology, geology and land cover. Ecohydrology, 9(7): 1141-1153. DOI:10.1002/eco.1712

Costigan, K. H., Kennard, M. J., Leigh, C., Sauquet, E., Datry, T. \& Boulton, A. J. (2017). Chapter 2.2 - Flow Regimes in Intermittent Rivers and Ephemeral Streams. In: Datry, T., Bonada, N., Boulton, A. (Eds.), Intermittent Rivers and Ephemeral Streams. Academic Press, pp. 51-78. DOI:https://doi.org/10.1016/B978-0-12-803835-2.00003-6

Datry, T., Larned, S. T. \& Tockner, K. (2014). Intermittent Rivers: A Challenge for Freshwater Ecology. BioScience, 64(3): 229-235. DOI:10.1093/biosci/bit027

Elith, J. \& Leathwick, J. R. (2009). Species Distribution Models: Ecological Explanation and Prediction Across Space and Time. Annual Review of Ecology, Evolution, and Systematics, 40(1): 677-697. DOI:10.1146/annurev.ecolsys.110308.120159

ESRI (2002). ArcGIS. Environmental Systems Research Institute, Redlands, CA, USA.

Freeman, E. A. \& Moisen, G. G. (2008). A comparison of the performance of threshold criteria for binary classification in terms of predicted prevalence and kappa. Ecological Modelling, 217(1-2): 48-58. DOI:10.1016/j.ecolmodel.2008.05.015

Frissell, C. A., Liss, W. J., Warren, C. E. \& Hurley, M. D. (1986). A hierarchical framework for stream habitat classification: Viewing streams in a watershed context. Environmental Management, 10(2): 199-214. DOI:10.1007/bf01867358

Fritz, K. M., Hagenbuch, E., D'Amico, E., Reif, M., Wigington, P. J., Leibowitz, S. G. et al. (2013). Comparing the Extent and Permanence of Headwater Streams From Two Field Surveys to Values From Hydrographic Databases and Maps. JAWRA Journal of the American Water Resources Association, 49(4): 867-882. DOI:doi:10.1111/jawr.12040

González-Ferreras, A. M. \& Barquín, J. (2017). Mapping the temporary and perennial character of whole river networks. Water Resources Research, 53(8): 6709-6724.

DOI:10.1002/2017wr020390

Haddadchi, A., Booker, D. J. \& Measures, R. J. (2018). Predicting river bed substrate cover proportions across New Zealand. CATENA, 163: 130-146.

DOI:https://doi.org/10.1016/j.catena.2017.12.014

Hanley, J. A. \& McNeil, B. J. (1982). The meaning and use of the area under a receiver operating characteristic (ROC) curve. Radiology, 143(1): 29-36.

DOI:10.1148/radiology.143.1.7063747

This article is protected by copyright. All rights reserved. 
Hermoso, V., Kennard, M. J. \& Linke, S. (2013a). Data Acquisition for Conservation Assessments: Is the Effort Worth It? PLOS ONE, 8(3): e59662.

DOI:10.1371/journal.pone.0059662

Hermoso, V., Ward, D. P. \& Kennard, M. J. (2012). Using water residency time to enhance spatio-temporal connectivity for conservation planning in seasonally dynamic freshwater ecosystems. Journal of Applied Ecology, 49(5): 1028-1035. DOI:10.1111/j.13652664.2012.02191.x

Hermoso, V., Ward, D. P. \& Kennard, M. J. (2013b). Prioritizing refugia for freshwater biodiversity conservation in highly seasonal ecosystems. Diversity and Distributions, 19(8): 1031-1042. DOI:10.1111/ddi.12082

Jaeger, K. L. \& Olden, J. D. (2012). Electrical Resistance Sensor Arrays as a Means to Quantify Longitudinal Connectivity of Rivers. River Research and Applications, 28(10): 18431852. DOI:10.1002/rra.1554

Jaeger, K. L., Olden, J. D. \& Pelland, N. A. (2014). Climate change poised to threaten hydrologic connectivity and endemic fishes in dryland streams. Proceedings of the National Academy of Sciences, 111(38): 13894-13899.

Jaeger, K. L., Sando, R., McShane, R. R., Dunham, J. B., Hockman-Wert, D. P., Kaiser, K. E. et al. (2019). Probability of Streamflow Permanence Model (PROSPER): A spatially continuous model of annual streamflow permanence throughout the Pacific Northwest. Journal of Hydrology X, 2: 100005. DOI:10.1016/j.hydroa.2018.100005

Larned, S. T., Datry, T., Arscott, D. B. \& Tockner, K. (2010). Emerging concepts in temporaryriver ecology. Freshwater Biology, 55(4): 717-738. DOI:10.1111/j.13652427.2009.02322.x

Leigh, C. \& Datry, T. (2016). Drying as a primary hydrological determinant of biodiversity in river systems: a broad-scale analysis. Ecography, 40(4): 487-499.

DOI:10.1111/ecog.02230

Leigh, C., Bonada, N., Boulton, A. J., Hugueny, B., Larned, S. T., Vander Vorste, R. \& Datry, T. (2016). Invertebrate assemblage responses and the dual roles of resistance and resilience to drying in intermittent rivers. Aquatic Sciences, 78(2): 291-301. DOI:10.1007/s00027015-0427-2

Leigh, C., Boulton, A. J., Courtwright, J. L., Fritz, K., May, C. L., Walker, R. H. \& Datry, T. (2015). Ecological research and management of intermittent rivers: an historical review and future directions. Freshwater Biology, 61(8): 1181-1199. DOI:10.1111/fwb.12646

Liaw, A. \& Wiener, M. (2002). Classification and Regression by randomForest. R News, 2(3): $18-22$.

Magoulick, D. D. \& Kobza, R. M. (2003). The role of refugia for fishes during drought: a review and synthesis. Freshwater Biology, 48(7): 1186-1198. DOI:10.1046/j.13652427.2003.01089.x

Moilanen, A., Leathwick, J. \& Elith, J. (2008). A method for spatial freshwater conservation prioritization. Freshwater Biology, 53(3): 577-592. DOI:10.1111/j.1365-

2427.2007.01906.x 
Montgomery, D. R. (1999). Process domains and the river continuum. JAWRA Journal of the American Water Resources Association, 35(2): 397-410. DOI:10.1111/j.17521688.1999.tb03598.x

Nash, J. E. \& Sutcliffe, J. V. (1970). River flow forecasting through conceptual models part I-A discussion of principles. Journal of hydrology, 10(3): 282-290.

Nel, J. L., Roux, D. J., Abell, R., Ashton, P. J., Cowling, R. M., Higgins, J. V. et al. (2009). Progress and challenges in freshwater conservation planning. Aquatic Conservation: Marine and Freshwater Ecosystems, 19(4): 474-485. DOI:doi:10.1002/aqc.1010

Reynolds, L. V., Shafroth, P. B. \& LeRoy Poff, N. (2015). Modeled intermittency risk for small streams in the Upper Colorado River Basin under climate change. Journal of Hydrology, 523: 768-780. DOI:10.1016/j.jhydrol.2015.02.025

Rose, P. M., Kennard, M. J., Moffatt, D. B., Sheldon, F. \& Butler, G. L. (2016). Testing Three Species Distribution Modelling Strategies to Define Fish Assemblage Reference Conditions for Stream Bioassessment and Related Applications. PLoS One, 11(1): e0146728. DOI:10.1371/journal.pone.0146728

Ruhí, A., Olden, J. D. \& Sabo, J. L. (2016). Declining streamflow induces collapse and replacement of native fish in the American Southwest. Frontiers in Ecology and the Environment, 14(9): 465-472.

Sabo, J. L. (2014). Predicting the river's blue line for fish conservation. Proceedings of the National Academy of Sciences, 111(38): 13686-13687.

Sedell, J. R., Reeves, G. H., Hauer, F. R., Stanford, J. A. \& Hawkins, C. P. (1990). Role of refugia in recovery from disturbances: Modern fragmented and disconnected river systems. Environmental Management, 14(5): 711-724. DOI:10.1007/bf02394720

Snelder, T. H., Datry, T., Lamouroux, N., Larned, S. T., Sauquet, E., Pella, H. \& Catalogne, C. (2013). Regionalization of patterns of flow intermittence from gauging station records. Hydrology and Earth System Sciences, 17(7): 2685-2699.

Stanley, E. H., Fisher, S. G. \& Grimm, N. B. (1997). Ecosystem expansion and contraction in streams. BioScience, 47(7): 427-435.

Stein, J. L., Hutchinson, M. F. \& Stein, J. A. (2014). A new stream and nested catchment framework for Australia. Hydrology and Earth System Sciences, 18(5): 1917-1933. DOI:10.5194/hess-18-1917-2014

Stein, J. L., Stein, J. \& Nix, H. A. (2002). Spatial analysis of anthropogenic river disturbance at regional and continental scales: identifying the wild rivers of Australia. Landscape and Urban Planning, 60(1): 1-25.

Steward, A. L., von Schiller, D., Tockner, K., Marshall, J. C. \& Bunn, S. E. (2012). When the river runs dry: human and ecological values of dry riverbeds. Frontiers in Ecology and the Environment, 10(4): 202-209. DOI:10.1890/110136

Svetnik, V., Liaw, A., Tong, C. \& Wang, T. (2004). Application of Breiman's Random Forest to Modeling Structure-Activity Relationships of Pharmaceutical Molecules. Multiple Classifier Systems. Springer Berlin Heidelberg, Berlin, Heidelberg, pp. 334-343. 
Turner, D. S. \& Richter, H. E. (2011). Wet/dry mapping: using citizen scientists to monitor the extent of perennial surface flow in dryland regions. Environmental management, 47(3): 497-505.

Uys, M. C. \& O'Keeffe, J. H. (1997). Simple Words and Fuzzy Zones: Early Directions for Temporary River Research in South Africa. Environmental Management, 21(4): 517-531. DOI:10.1007/s002679900047

van Dijk, A. I. J. M. (2010). The Australian Water Resources Assessment System. Technical Report 3. Landscape Model (version 0.5) Technical Description. CSIRO: Water for a Healthy Country National Research Flagship.

Viney, N., Vaze, J., Crosbie, R., Wang, B., Dawes, W. \& Frost, A. (2015). AWRA-L v5.0: Technical description of model algorithms and inputs. CSIRO, Australia.

Ward, D. P., Petty, A., Setterfield, S. A., Douglas, M. M., Ferdinands, K., Hamilton, S. K. \& Phinn, S. (2014). Floodplain inundation and vegetation dynamics in the Alligator Rivers region (Kakadu) of northern Australia assessed using optical and radar remote sensing. Remote Sensing of Environment, 147: 43-55. DOI:10.1016/j.rse.2014.02.009

Yu, S., Bond, N. R., Bunn, S. E., Xu, Z. \& Kennard, M. J. (2018). Quantifying spatial and temporal patterns of flow intermittency using spatially contiguous runoff data. Journal of Hydrology, 559: 861-872. DOI:10.1016/j.jhydrol.2018.03.009 
Table 1. Table of environmental predictor variables used in the statistical modelling of surface water extent. Environmental data were sourced from Stein et al. 2014 except where indicated.

\begin{tabular}{|c|c|c|c|c|}
\hline $\begin{array}{l}\text { Hydrological } \\
\text { process }\end{array}$ & Spatial scale & Predictor variable & Description & Unit \\
\hline \multirow[t]{6}{*}{ Water gains } & Climate & CATANNRAIN & Catchment average annual mean rainfall & $\mathrm{mm}$ \\
\hline & Catchment & $\begin{array}{l}\text { CatRain } 10_{1} \\
\text { CATSTORAGE }\end{array}$ & $\begin{array}{l}\text { Catchment average rainfall over last } 10 \text { days } \\
\text { Catchment storage, describing the relative proportion of depositional areas } \\
\text { in the contributing catchment }\end{array}$ & $\begin{array}{l}\mathrm{mm} \\
\%\end{array}$ \\
\hline & & RUNANNCOFV & Coefficient of variation of annual totals of accumulated soil water surplus & / \\
\hline & & RUNANNMEAN & Annual mean accumulated soil water surplus & ML \\
\hline & & CAT_A_KAST & Catchment average saturated hydraulic conductivity & $\mathrm{mm} / \mathrm{h}$ \\
\hline & Stream segment & Discharge $10_{2}$ & Mean discharge over the last 10 days & ML/day \\
\hline \multirow[t]{4}{*}{ Water losses } & Climate & CATDRYQTEMP & Catchment average driest quarter mean temperature & ${ }^{\circ} \mathrm{C}$ \\
\hline & Catchment & $\mathrm{SubETA}_{10}$ & Sub-catchment actual evapotranspiration over last 10 days & $\mathrm{mm}$ \\
\hline & & CAT_SOLPAWHC & Catchment average solum plant available water holding capacity & $\mathrm{mm}$ \\
\hline & Stream segment & STR-UNCONSOLIDATED & stream and valley percentage unconsolidated rocks & $\%$ \\
\hline \multirow{7}{*}{$\begin{array}{l}\text { Surface } \\
\text { water } \\
\text { resistance }\end{array}$} & Catchment & CATELEMAX & Maximum upstream elevation & $\mathrm{m}$ \\
\hline & & ELONGRATIO & Catchment shape (elongation ratio) & / \\
\hline & Stream segment & RDI & River disturbance index & l \\
\hline & & SubSlope & Segment sub-catchment average slope & $\circ$ \\
\hline & & StrOrder & Strahler stream order & I \\
\hline & & FlowInterm $_{4}$ & Flow intermittency represented by mean zero flow durations (months) & / \\
\hline & & DaysNoFlow $_{5}$ & Number of days since cease to flow & Days \\
\hline
\end{tabular}

Data source: 1, 2, 3, and 5 are calculated based on the inputs to and output from the AWRA-L model; 4 is sourced from Yu et al. (2018).

This article is protected by copyright. All rights reserved. 
Table 2. Values of various model performance metrics for the trained model and the internal and external validations for each of the three response variable types. MAE, mean absolute error; RMSE, root-mean-square error; NSE, Nash-Sutcliffe model efficiency coefficient; AUC, area under the curve (receiver operating characteristic); CCR, correct classification rate; Kappa, 9 Cohen's kappa. Refer to Section 3.4 for more details on the model performance metrics.

\begin{tabular}{|c|c|c|c|c|c|c|c|c|c|c|}
\hline \multirow{2}{*}{\multicolumn{2}{|c|}{$\begin{array}{l}\text { Model types } \\
\text { Performance metric }\end{array}$}} & \multicolumn{3}{|c|}{$\begin{array}{l}\text { Continuous surface } \\
\text { water model }\end{array}$} & \multicolumn{3}{|c|}{$\begin{array}{l}\text { Surface water } \\
\text { presence/absence } \\
\text { model }\end{array}$} & \multicolumn{3}{|c|}{$\begin{array}{l}\text { High-quality refuge } \\
\text { model }\end{array}$} \\
\hline & & MAE & RMSE & NSE & AUC & CCR & Kappa & AUC & CCR & Kappa \\
\hline \multicolumn{2}{|c|}{ Model fit (LOOCV) } & 0.22 & 0.31 & 0.51 & 0.86 & 0.84 & 0.45 & 0.90 & 0.82 & 0.62 \\
\hline \multirow{6}{*}{$\begin{array}{l}\text { Internal } \\
\text { validation } \\
(\mathrm{n}=15)\end{array}$} & Mar & 0.22 & 0.29 & 0.65 & 0.84 & 0.93 & 1.00 & 0.96 & 0.87 & 0.72 \\
\hline & May & 0.21 & 0.25 & 0.71 & 1.00 & 0.87 & 0.71 & 1.00 & 1.00 & 1.00 \\
\hline & Jul & 0.28 & 0.32 & 0.55 & 0.89 & 0.87 & 0.73 & 0.94 & 0.93 & 0.87 \\
\hline & Sep & 0.31 & 0.37 & 0.36 & 0.88 & 0.80 & 0.60 & 0.83 & 0.80 & 0.59 \\
\hline & Nov & 0.19 & 0.26 & 0.73 & 0.96 & 0.80 & 0.59 & 1.00 & 1.00 & 1.00 \\
\hline & Overall & 0.24 & 0.29 & 0.63 & 0.84 & 0.85 & 0.69 & 0.87 & 0.87 & 0.73 \\
\hline \multirow{6}{*}{$\begin{array}{l}\text { External } \\
\text { validation } \\
(\mathrm{n}=10)\end{array}$} & Mar & 0.19 & 0.34 & 0.47 & 0.64 & 0.70 & 0.21 & 0.96 & 0.80 & 0.55 \\
\hline & May & 0.34 & 0.45 & 0.11 & 0.74 & 0.70 & 0.21 & 1.00 & 0.70 & 0.40 \\
\hline & Jul & 0.36 & 0.49 & -0.11 & 0.88 & 0.80 & 0.55 & 0.52 & 0.70 & 0.40 \\
\hline & Sep & 0.46 & 0.59 & -1.30 & 0.84 & 0.70 & 0.4 & 0.52 & 0.50 & 0.19 \\
\hline & Nov & 0.12 & 0.19 & 0.79 & 1.00 & 1.00 & 1.00 & 1.00 & 0.90 & 0.74 \\
\hline & Overall & 0.30 & 0.43 & 0.14 & 0.81 & 0.82 & 0.57 & 0.85 & 0.76 & 0.51 \\
\hline
\end{tabular}


10 Table 3. Ranking of retained predictor variable importance for predicting surface water extent 11 for each response variable type. Ranking of 1 indicates the most important. Bold predictors were 12 shared in all three RF models.

\begin{tabular}{lcccc}
\hline Model type & $\begin{array}{l}\text { Continuous surface } \\
\text { water model }\end{array}$ & $\begin{array}{l}\text { Surface water } \\
\text { presence/absence } \\
\text { model }\end{array}$ & $\begin{array}{l}\text { High-quality refuge } \\
\text { model }\end{array}$ & Average \\
\hline RUNANNCOFV & 1 & 1 & 1 & 1 \\
StrOrder & & & 2 & 2 \\
SubSlope & 2 & & 5 & 2 \\
FlowInterm & 3 & 3 & 3 & 3.7 \\
Discharge10 & 5 & & 4 & 4 \\
CATDRYQTEMP & & 2 & 6 & 4 \\
CATANNRAIN & 4 & 4 & 7 & 4 \\
SubETA10 & 7 & & 8 & 6 \\
CAT_A_KAST & 6 & & & 7 \\
\hline
\end{tabular}

This article is protected by copyright. All rights reserved. 


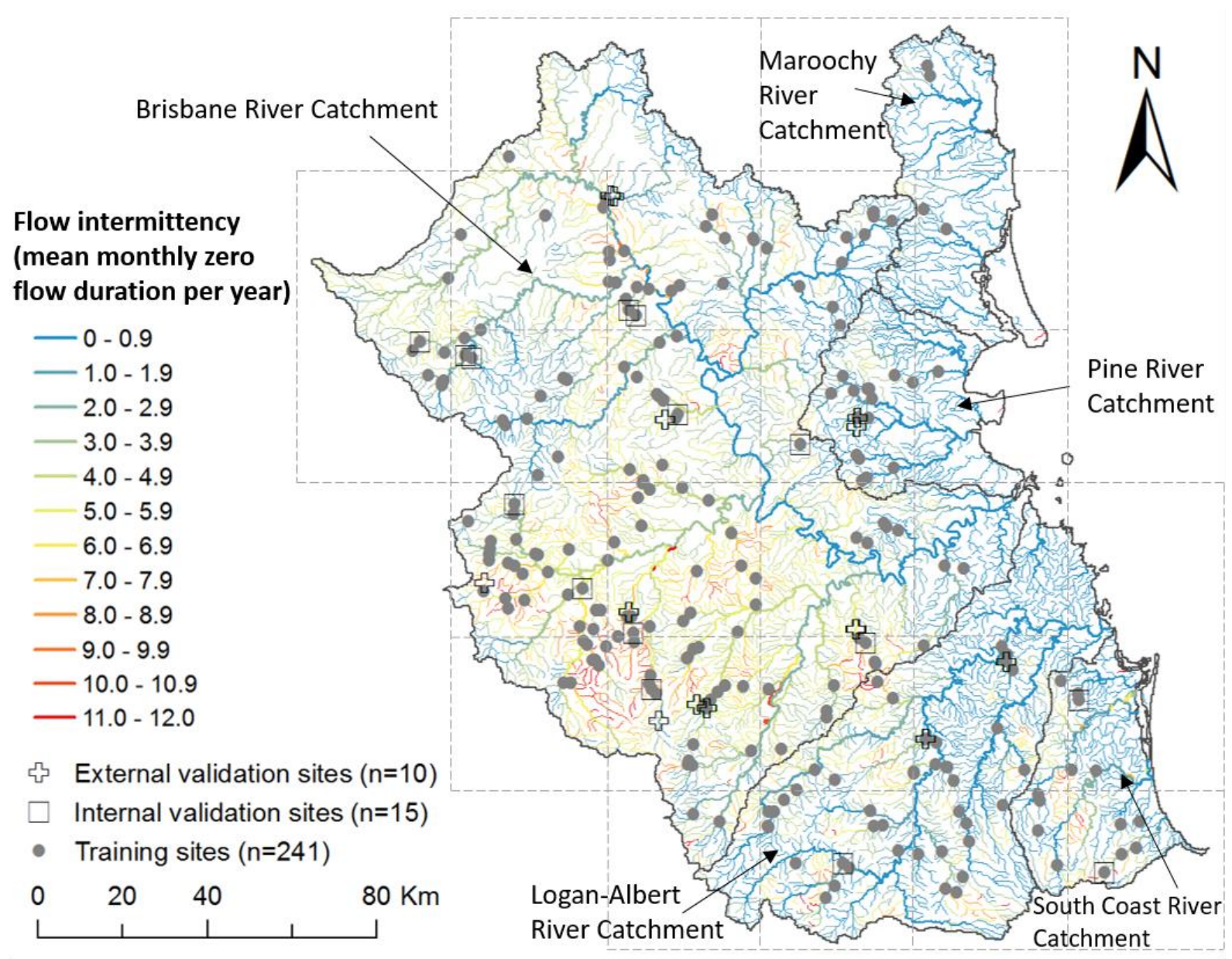

Figure 1. Locations of sampling sites across south eastern Queensland. The dashed grey rectangles divide the study area into 24 evenly-sized cells which were used for stratified site selection. The number of sites for each dataset is indicated in parentheses. The river network is color-coded according to relative flow intermittency (source: Yu et al. 2018). 
Time of sampling

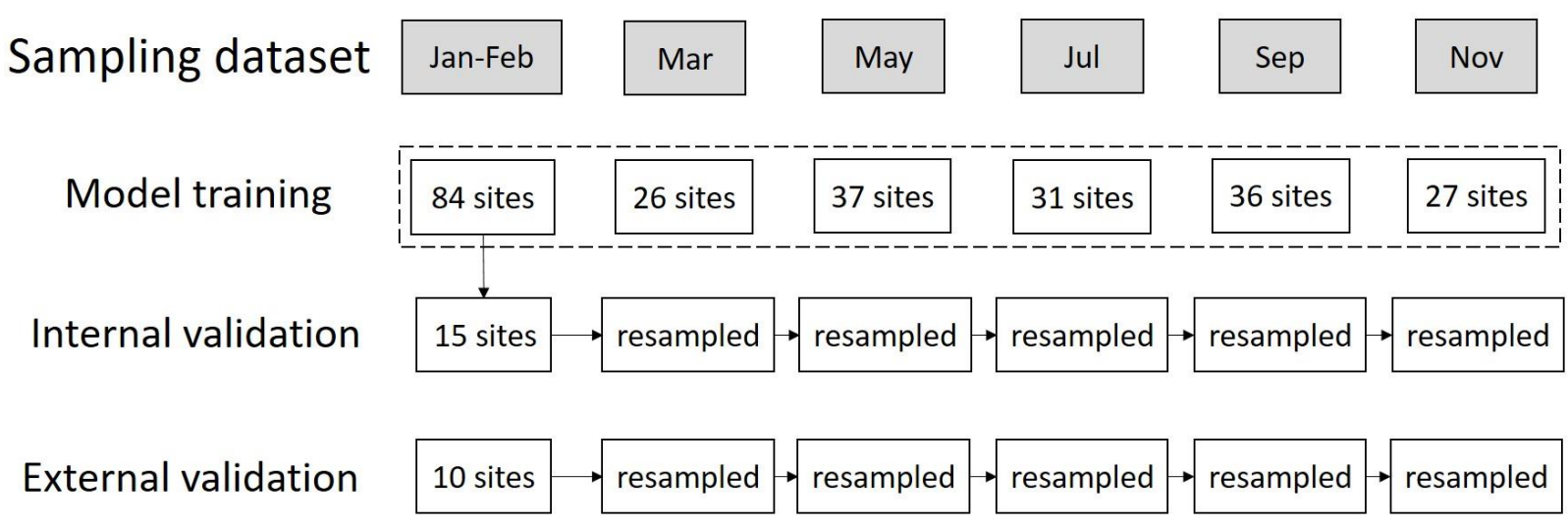

Figure 2. Schematic of the sampling strategy. Eighty-four of these sites were sampled in January / February. A subset of sites (ranging from 26 and 37 sites) were sampled bimonthly thereafter. These sites were used to train the predictive model (termed 'training' sites). A subset of 15 randomly selected training sites (termed 'internal validation' sites) was sampled bimonthly and was used to evaluate the stability of model predictions through time. An additional set of 10 randomly selected new sites was sampled bimonthly and used to externally validate the model performance. 

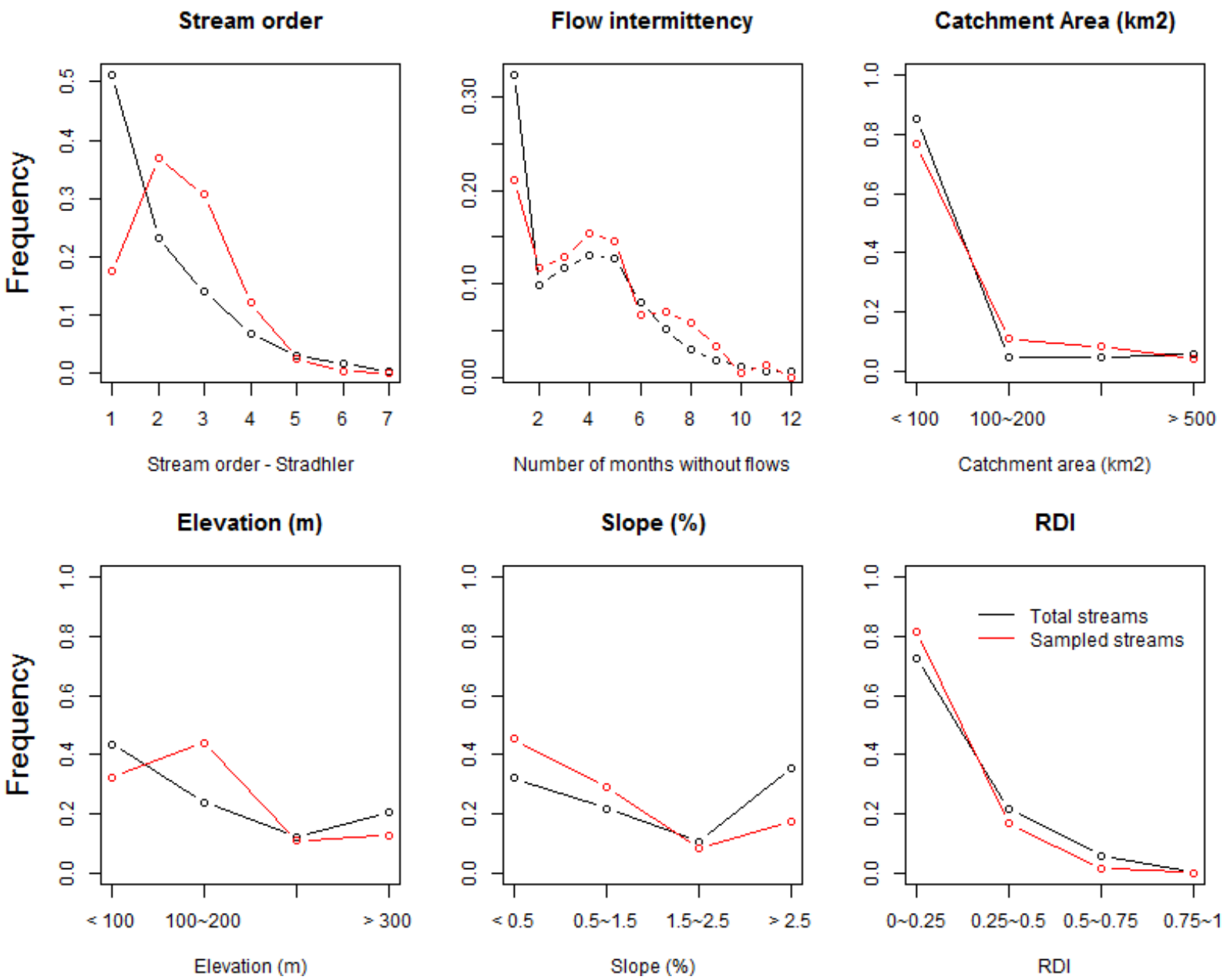

Figure 3. All 241 training sites as a whole were checked for their representativeness for the entire river networks within SEQ by comparing the distributions of certain environmental attributes of the sampled streams and that of the total streams. This figure shows comparison of the distribution of Strahler stream order, flow intermittency, catchment area, the average subcatchment elevation, the mean slope of the surveyed stream segment and River Disturbance Index (RDI) between the total and the sampled streams. 


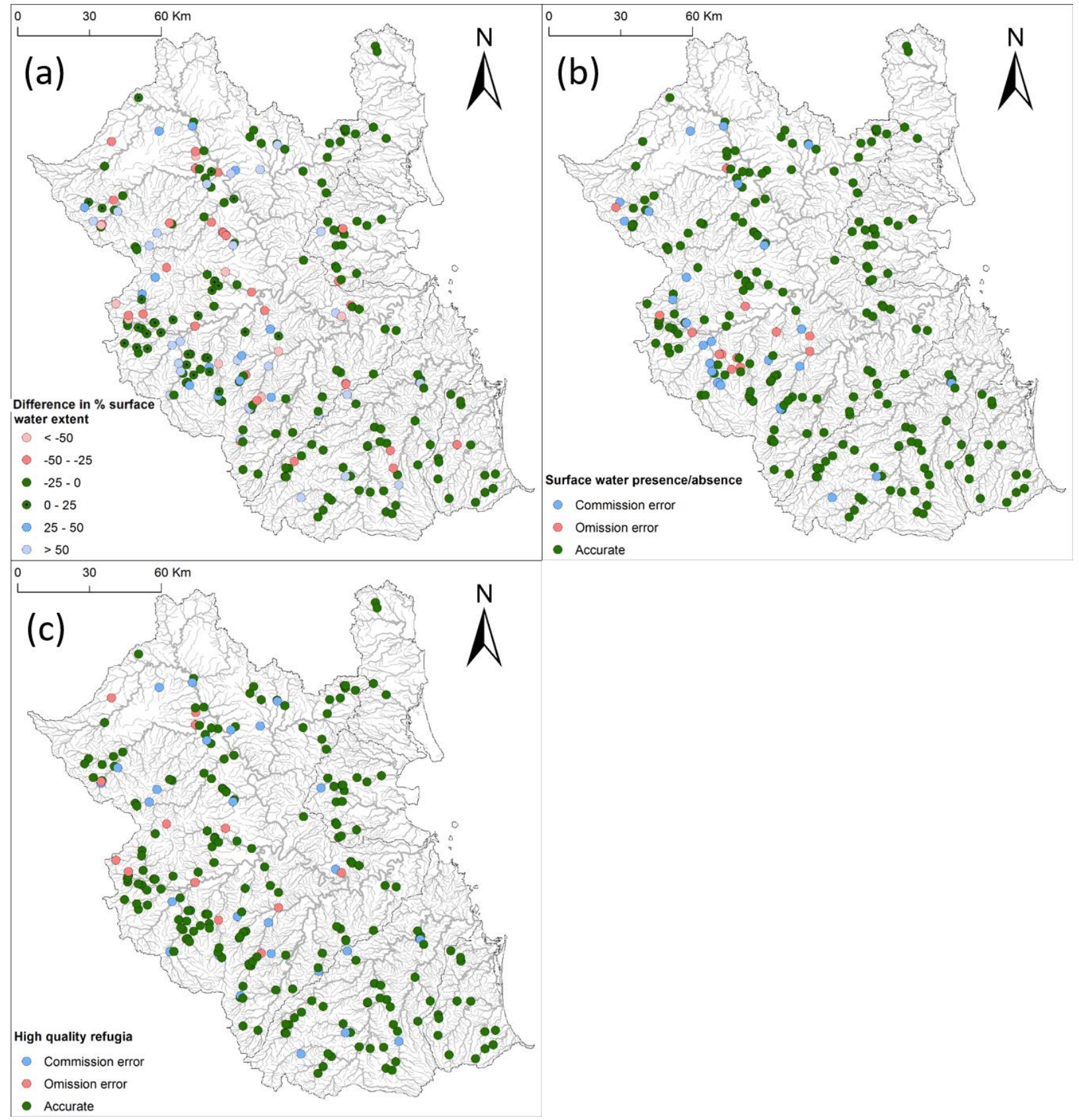

Figure 4. Comparison of the predicted and observed surface water extent for the three models: (a) the continuous surface water extent model, where the training sites were colored by the difference in \% surface water extent between the predicted and observed (i.e. the green color represents little bias, the blue spectrum represents under-estimation, while the red spectrum indicates over-estimation; the lighter the color is, the more biased the estimate is); (b) the surface water presence/absence model, where the sites rightly predicted were in green, while the sites wrongly classified were in blue if caused by commission error or in red if caused by omission error; (c) the high-quality refuge model (i.e. > 50\% surface water), and the sites were colored in the same way as in (b). 


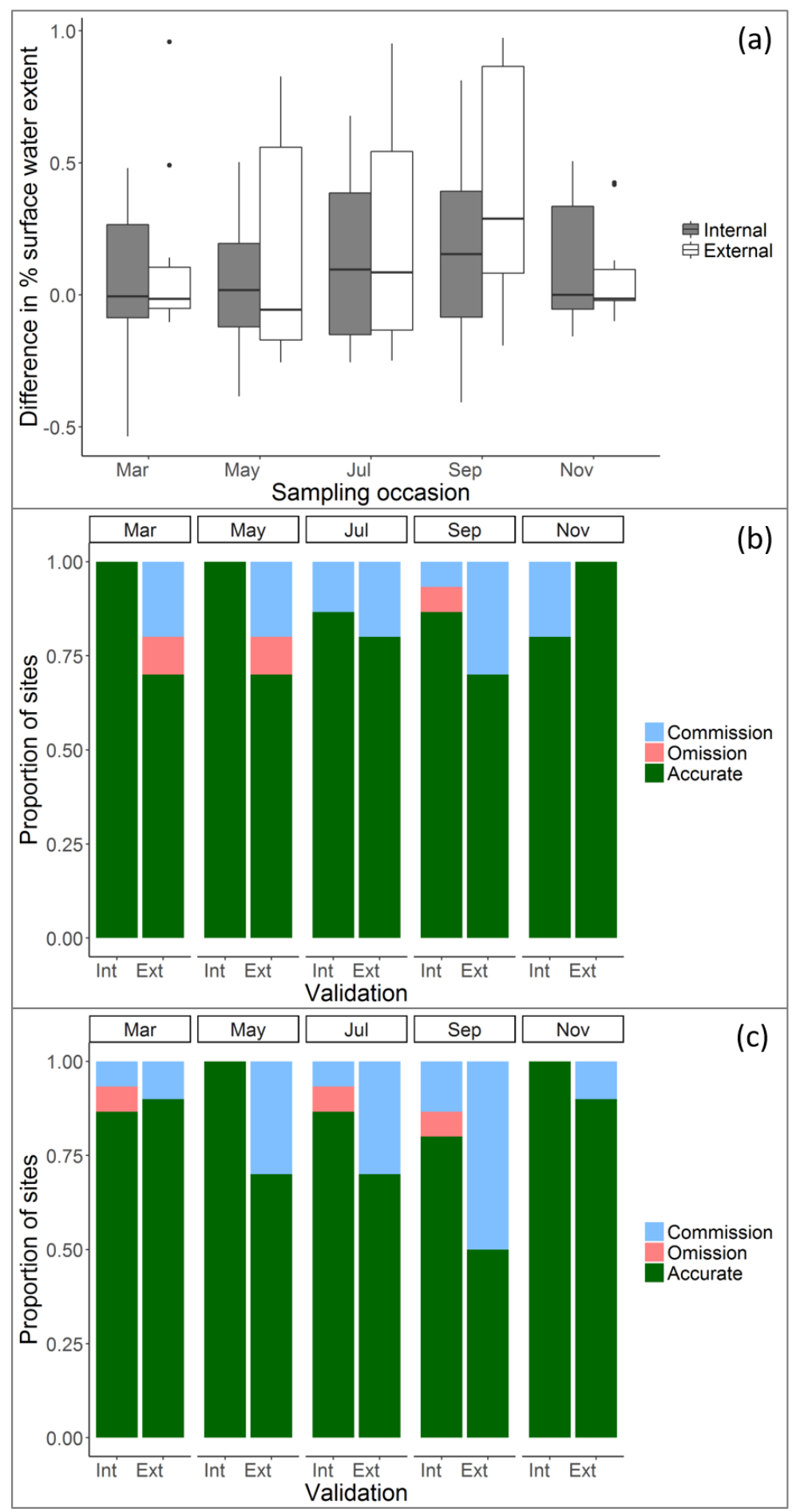

Figure 5. Comparison between the predicted and observed surface water extent for the external and internal validation samples for each of the three RF models: (a) the continuous surface water model, where difference in \% surface water extent is shown as boxplot; (b) the surface water presence/absence model and (c) high-quality aquatic refuge model. For both of the classification models, the proportions of sample size for commission error, omission error and accurate predictions are shown over time. 


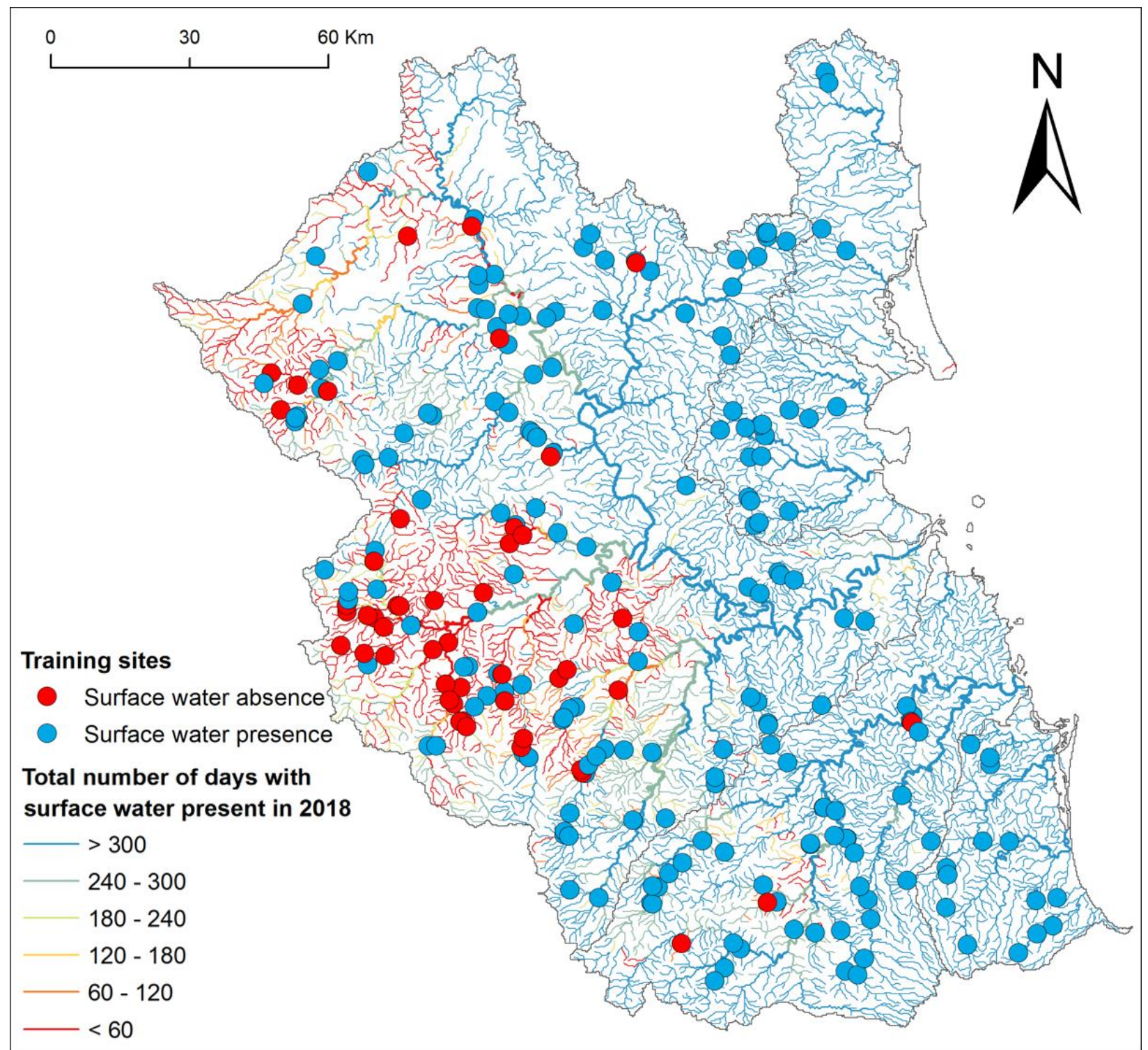

Figure 6. Spatial variation in the predicted total number of days with surface water presence/absence during 2018 (the year in which the field sampling occurred) across the river networks in SEQ. The observed surface water presence/absence is also shown (blue and red for surface water presence/absence, respectively). 


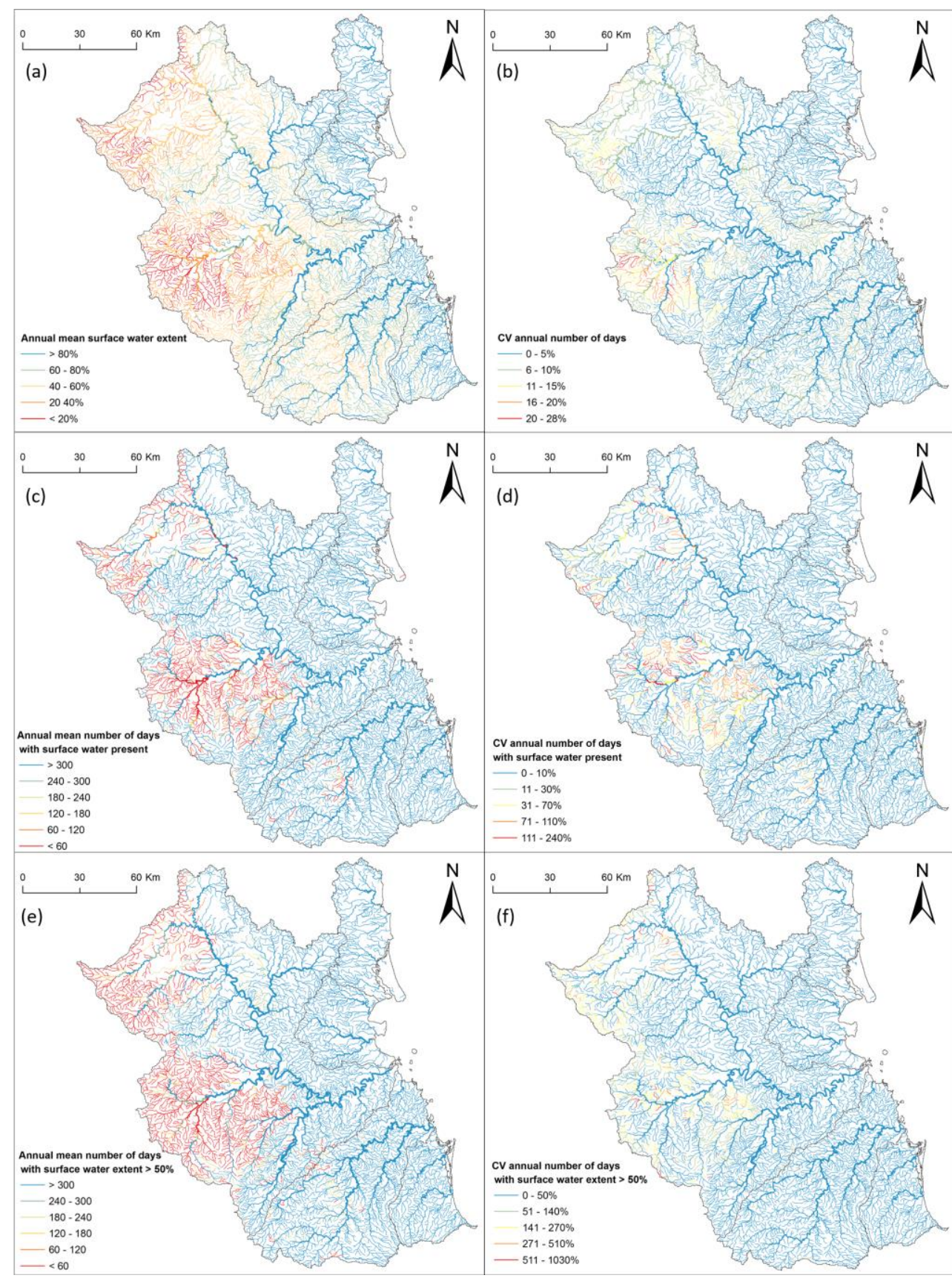

Figure 7. Spatial variation in annual mean surface water extent and its coefficient of variation (CV) predicted by the random forest models for continuous surface water extent (a \& b), surface water presence/absence (c \& d), and high-quality refuges (e \& f). 

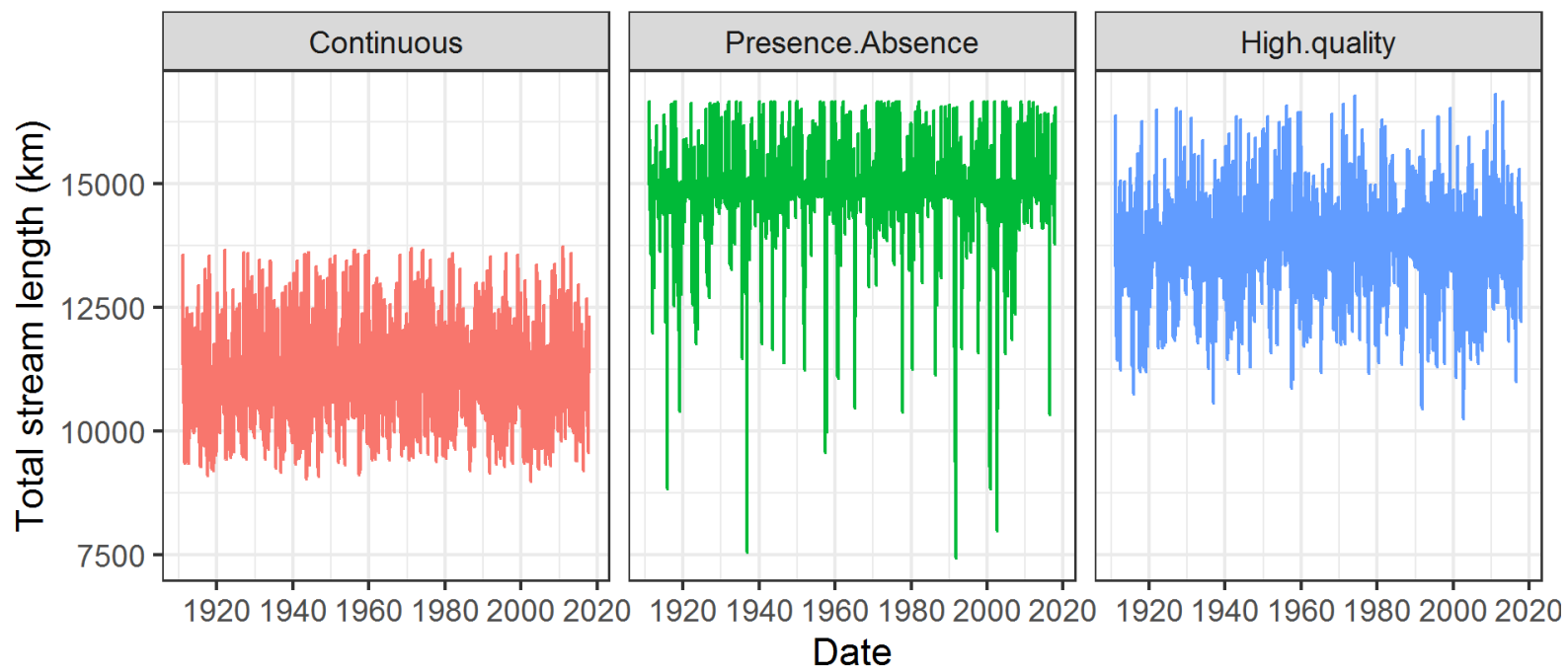

Figure 8. Simulated daily variation total stream length containing surface water for each of the three response variables over the period of 1911-2017. 


\section{Time of sampling}

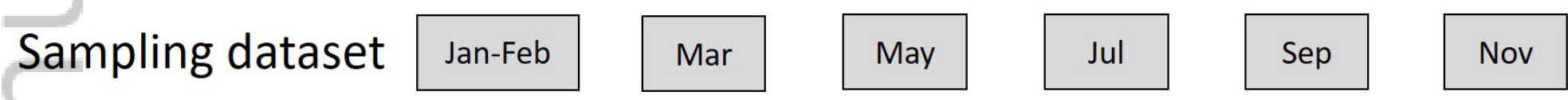

Model training

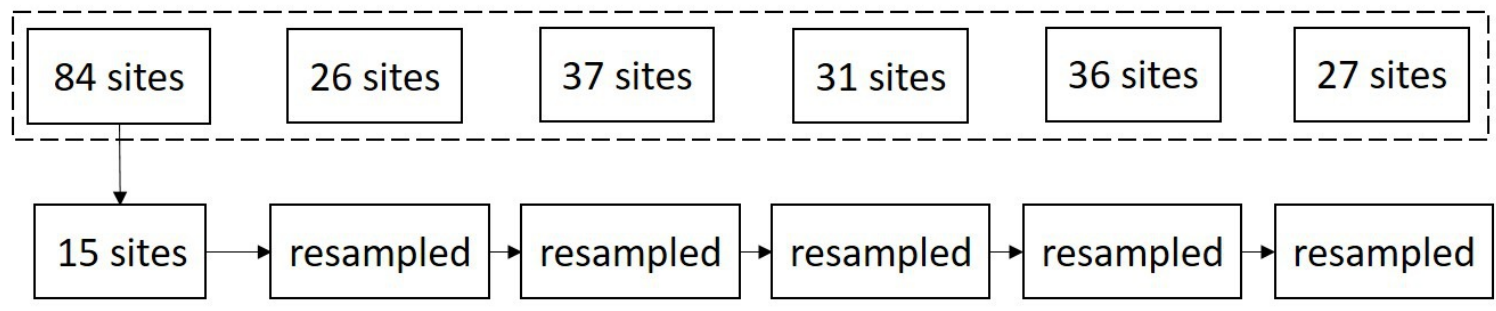

External validation

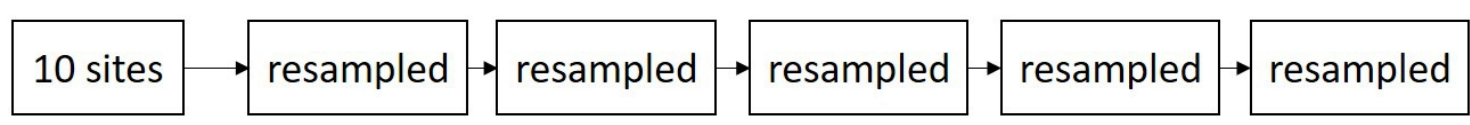

2019WR025216-f02-z-.jpg 


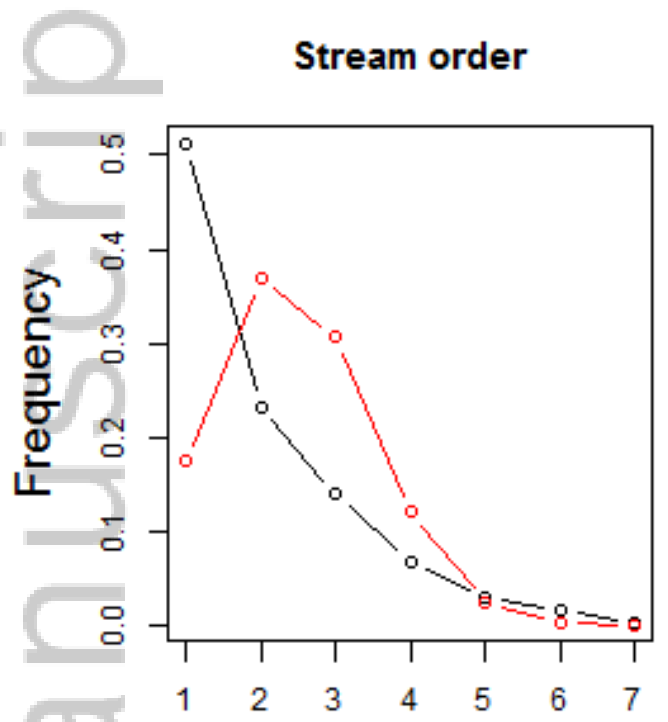

Stream order - Stradhler

Elevation (m)

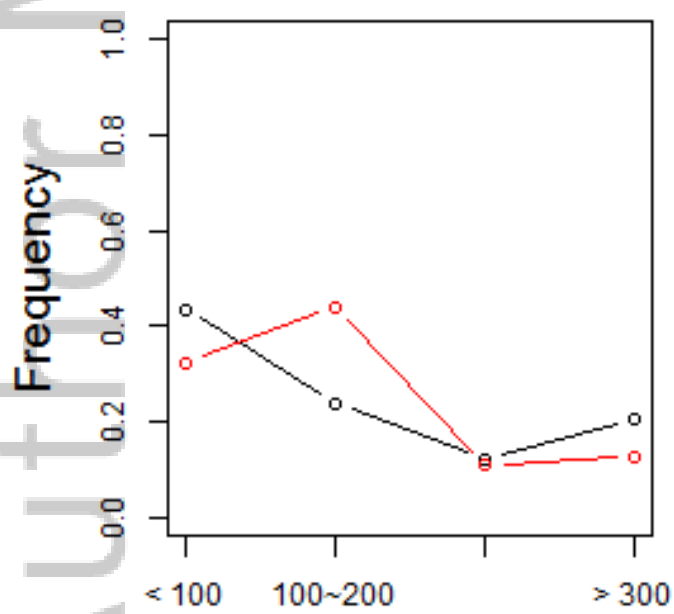

Elevation (m)
Flow intermittency

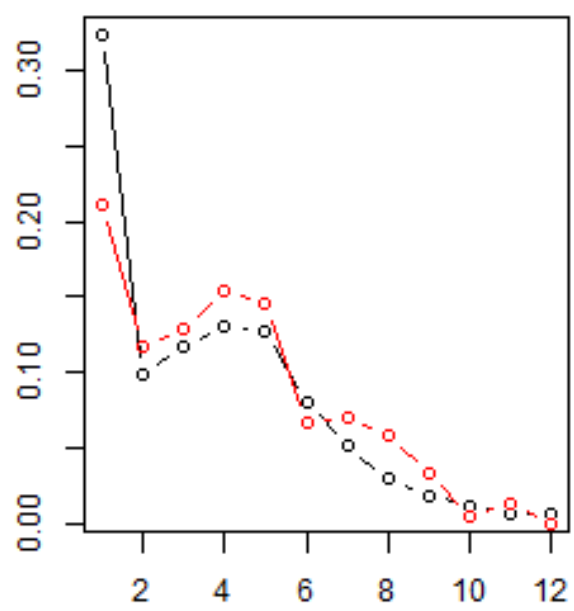

Number of months without flows

Slope (\%)

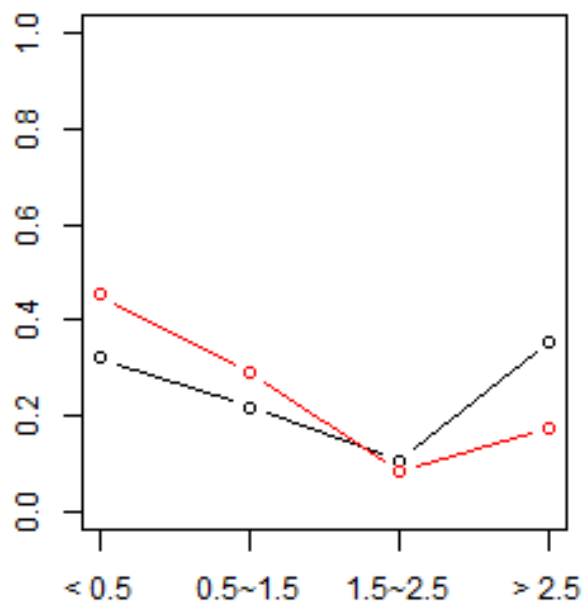

Slope (\%)

2019WR025216-f03-z-.png
Catchment Area (km2)

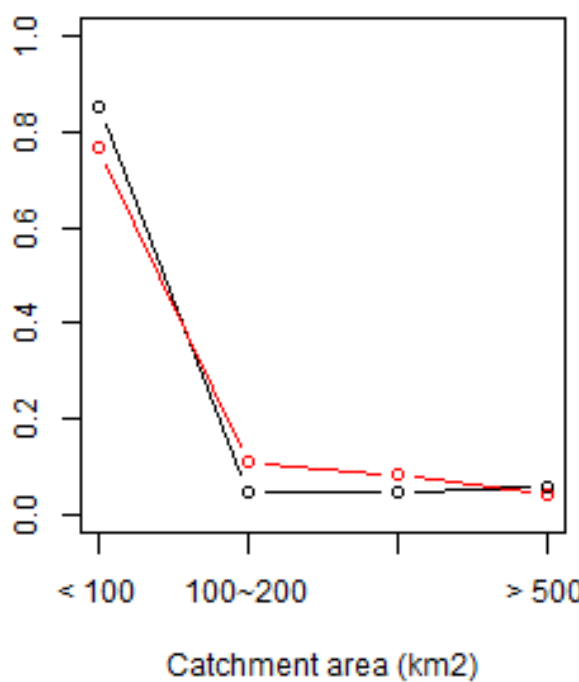

RDI

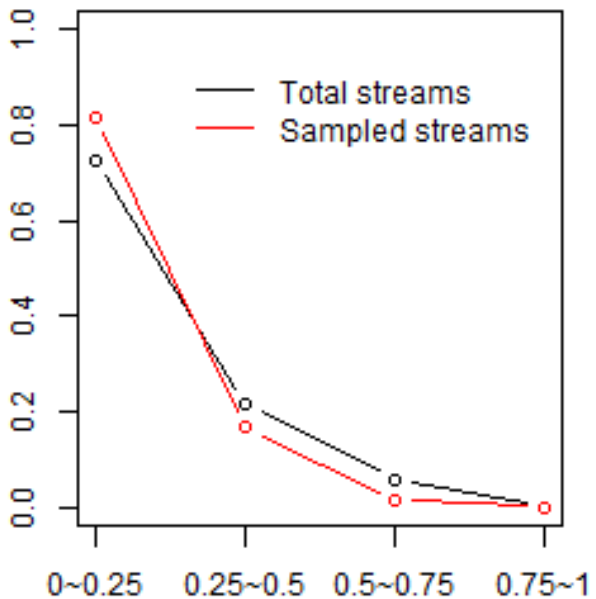

RDI 


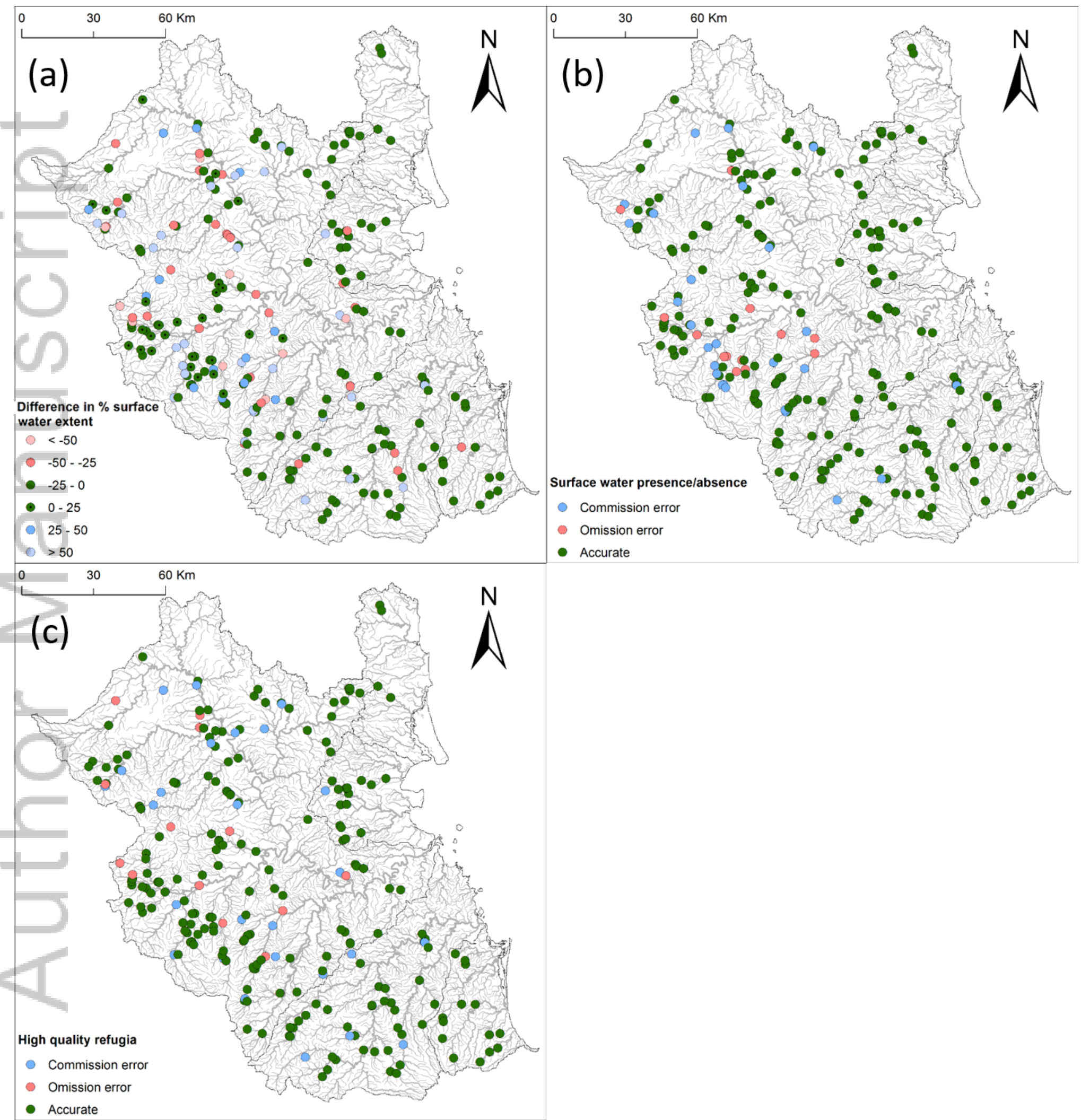

2019WR025216-f04-z-.png

This article is protected by copyright. All rights reserved. 


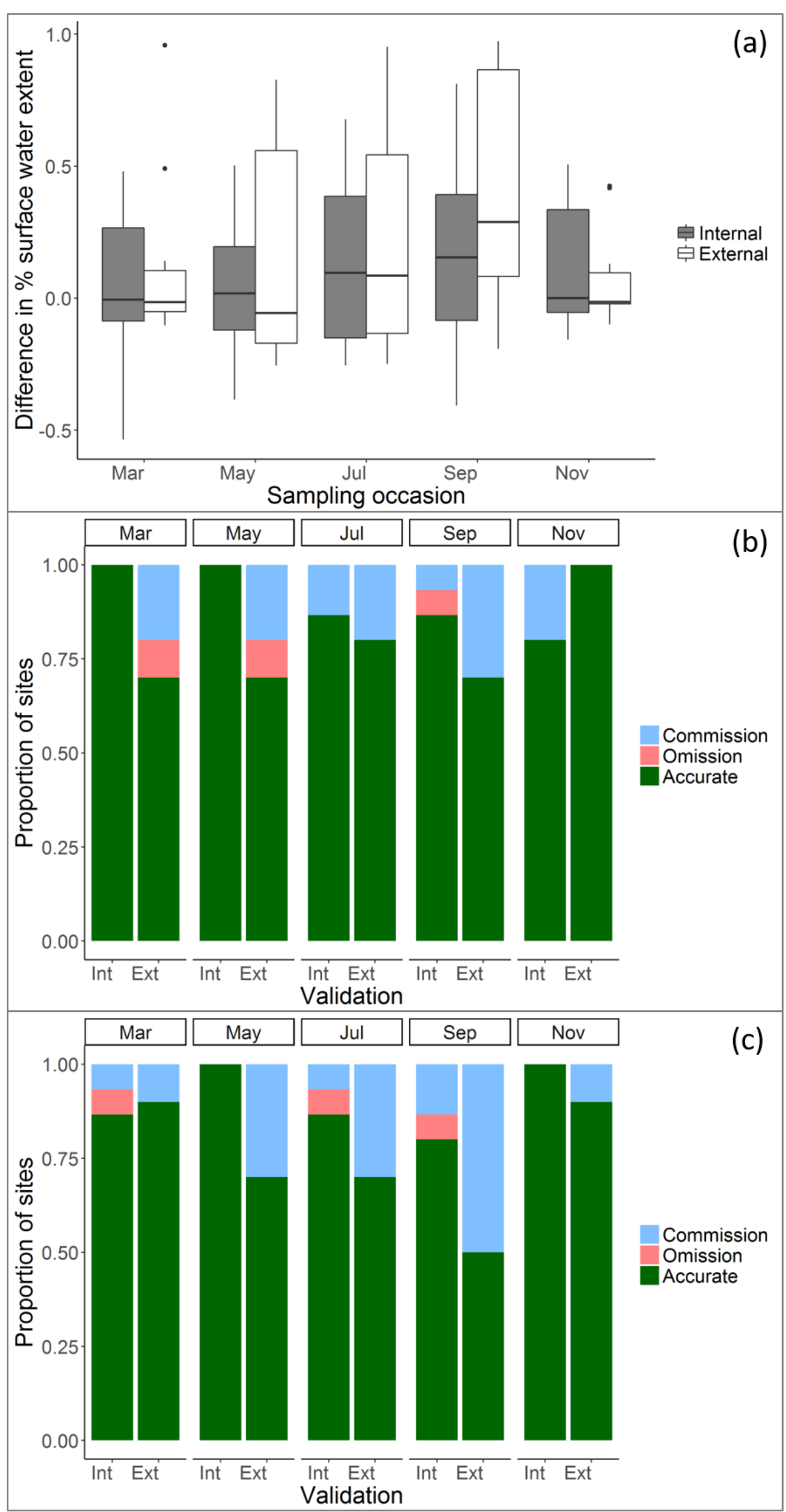

2019WR025216-f05-z-.png

This article is protected by copyright. All rights reserved. 


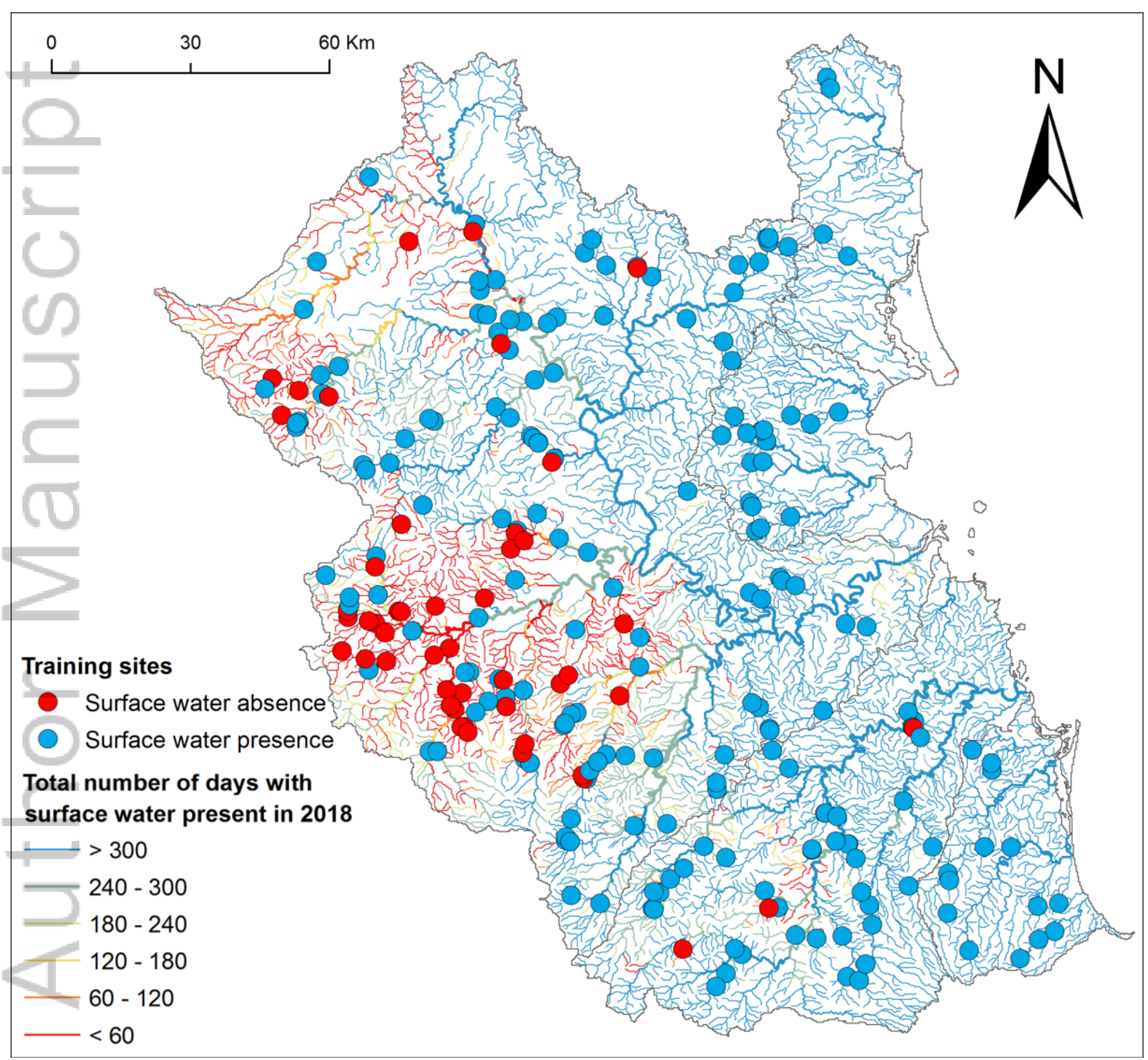

2019WR025216-f06-z-.png

This article is protected by copyright. All rights reserved. 


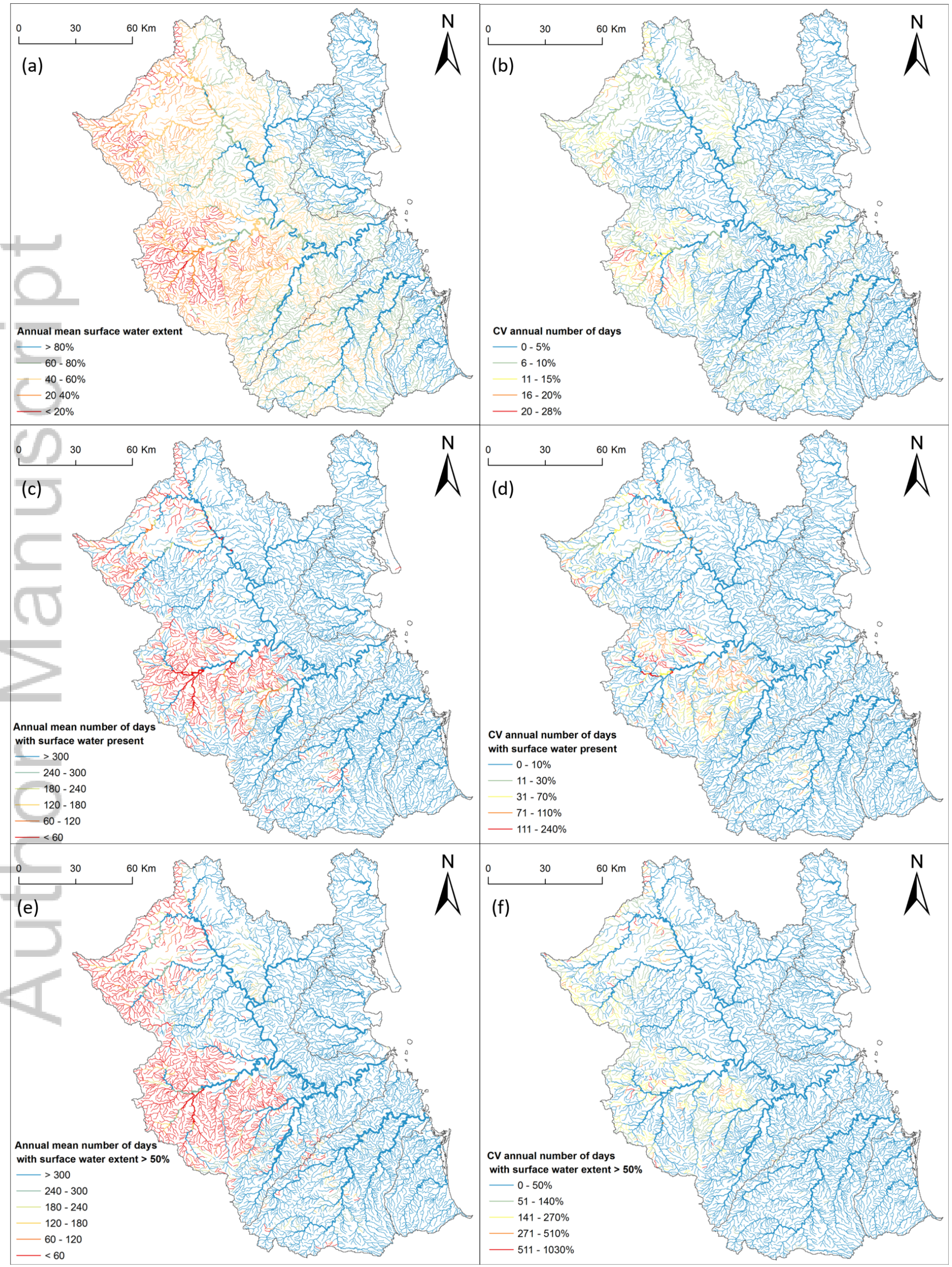

This article is protecteg by 

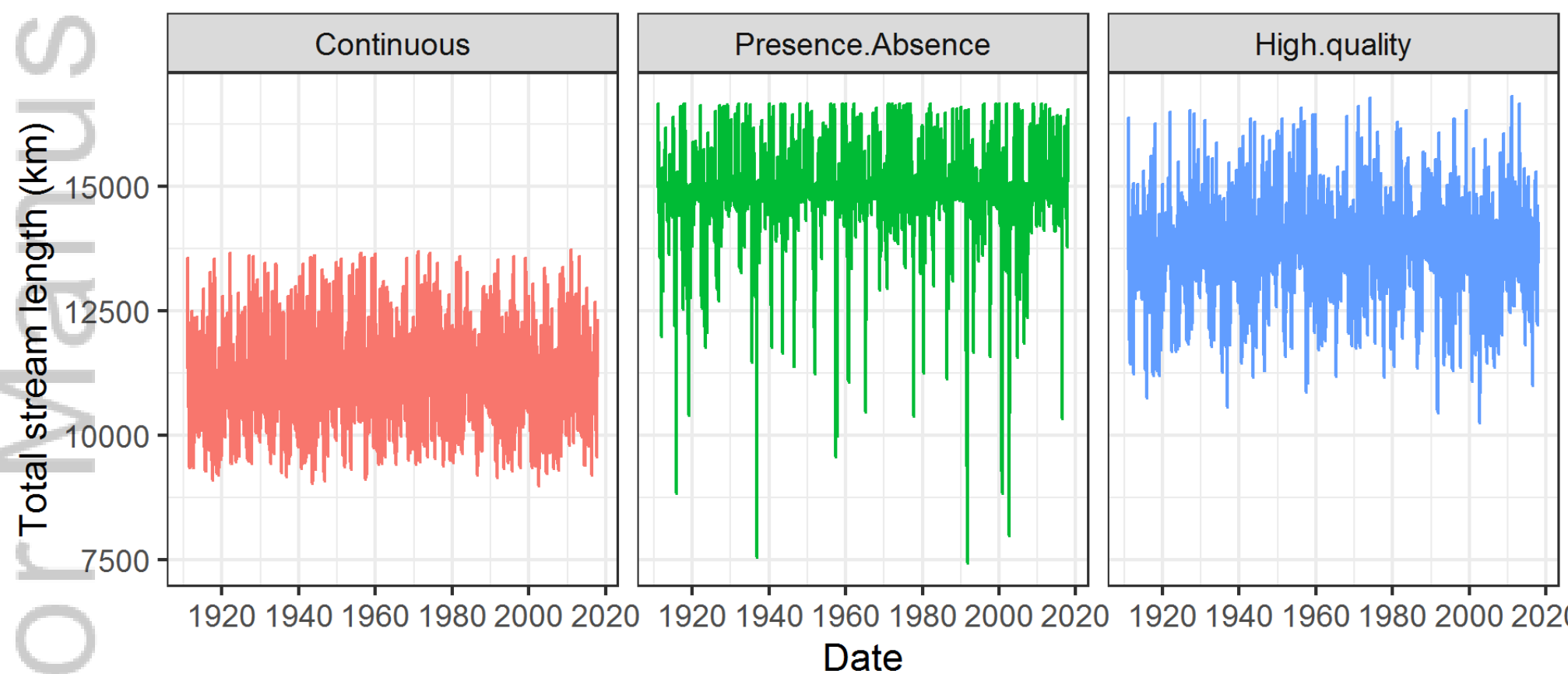

Date

2019WR025216-f08-z-.png

This article is protected by copyright. All rights reserved. 


\section{University Library}

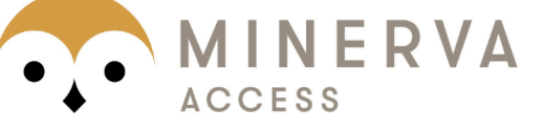

A gateway to Melbourne's research publications

Minerva Access is the Institutional Repository of The University of Melbourne

Author/s:

Yu, S;Bond, NR;Bunn, SE;Kennard, MJ

Title:

Development and Application of Predictive Models of Surface Water Extent to Identify Aquatic Refuges in Eastern Australian Temporary Stream Networks

Date:

2019-11-01

Citation:

Yu, S., Bond, N. R., Bunn, S. E. \& Kennard, M. J. (2019). Development and Application of Predictive Models of Surface Water Extent to Identify Aquatic Refuges in Eastern Australian Temporary Stream Networks. WATER RESOURCES RESEARCH, 55 (11), pp.9639-9655. https://doi.org/10.1029/2019WR025216.

Persistent Link:

http://hdl.handle.net/11343/286569 